\title{
Kernos
}

Revue internationale et pluridisciplinaire de religion grecque antique

$30 \mid 2017$

Varia

\section{Apollon Sarpédonios et les influences culturelles à Séleucie-du-Kalykadnos}

\author{
Adrien Berthou
}

\section{(2) OpenEdition \\ Journals}

Édition électronique

URL : http://journals.openedition.org/kernos/2498

DOI : 10.4000/kernos.2498

ISSN : 2034-7871

Éditeur

Centre international d'étude de la religion grecque antique

Édition imprimée

Date de publication : 1 octobre 2017

Pagination : 221-254

ISSN : 0776-3824

Référence électronique

Adrien Berthou, «Apollon Sarpédonios et les influences culturelles à Séleucie-du-Kalykadnos », Kernos [En ligne], 30 | 2017, mis en ligne le 01 octobre 2019, consulté le 17 septembre 2020. URL : http:// journals.openedition.org/kernos/2498; DOI : https://doi.org/10.4000/kernos.2498

Ce document a été généré automatiquement le 17 septembre 2020.

Kernos 


\title{
Apollon Sarpédonios et les influences culturelles
}

\section{à Séleucie-du-Kalykadnos}

\author{
Adrien Berthou
}

\section{Introduction}

1 La région de l'embouchure du Kalykadnos (act. Göksu) est par sa position stratégique une étape importante dans les échanges internationaux du monde antique. Au carrefour de la route ouest-est entre le monde égéen et le Levant d'une part, et de la route nord-sud reliant le plateau anatolien et Chypre via la vallée du Kalykadnos d'autre part, cette région de passage est soumise à des échanges culturels intenses et permanents.

2 L'histoire politique et culturelle de cette région ne peut être retracée que par bribes éparses et les sources à disposition sont sujettes à de nombreux débats, particulièrement lorsqu'elles se rapportent aux périodes les plus anciennes ${ }^{1}$. Néanmoins, plusieurs sources évoquent entre le XIII et le $\mathrm{v}^{\mathrm{e}}$ siècle av. J.-C, la cité d'Ura, « la grande » en louvite ${ }^{2}$, qui semble correspondre à la cité hellénistique et romaine de Séleucie-du-Kalykadnos (act. Silifke) ${ }^{3}$. À la fin du II millénaire, cette importante cité marchande située entre le TarHुuntašša louvite et le Kizzuwatna hourrito-louvite entretient d'intenses relations avec l'Empire hittite dont elle dépend vraisemblablement, ainsi qu'avec Chypre et la syrienne Ougarit. Elle disparait ensuite des sources au début du I ${ }^{\text {er }}$ millénaire avant J.-C. pour réapparaître au vIII siècle quand Néo-assyriens et Phrygiens se disputent la basse vallée du Kalykadnos qui fait office de «zone tampon» entre les deux empires. Les premiers établissements grecs et phéniciens, comptoirs de commerce voire colonies, pourraient s'être implantés en Cilicie à cette période. Les sources néo-babyloniennes mentionnent ensuite la cité d'Ura, capitale du royaume de Pirindu qui pourrait recouvrir une large partie de la future Cilicie Trachée jusqu'au début de l'époque achéménide ${ }^{4}$. Sous la domination 
perse, le centre du pouvoir local semble alors se déplacer d'Ura vers Holmoi ${ }^{5}$, qui devient une cité portuaire importante et stratégique pour le Grand Roi, tout en restant le port, voire l'arsenal d'Ura ${ }^{6}$.

3 Ammien Marcellin et Stéphane de Byzance ${ }^{7}$ rapportent ensuite la fondation de la cité de Séleucie-du-Kalykadnos par Séleucos Nikatôr au début du III siècle av. J.-C., peuplée dès sa création par les habitants de la cité voisine de Holmoi d'après Strabon ${ }^{8}$. Refondée à l'époque hellénistique, la cité d'Ura devenue Séleucie-du-Kalykadnos retrouve ainsi son rang de capitale régionale. Elle conserve son importance jusqu'à la fin de l'époque romaine, en particulier lorsqu'elle est promue capitale de la province autonome d'Isaurie sous Gordien III puis devient un centre de pèlerinage renommé du culte de sainte Thècle aux IV et $\mathrm{V}^{\mathrm{e}}$ siècles ap. J.-C.

4 Les monnaies d'époque perse de Holmoi puis hellénistique et romaine de Séleucie représentent très fréquemment Apollon qui apparaît comme la principale divinité de ces deux cités. Plusieurs sources littéraires ${ }^{9}$ attribuent à ce dernier l'épithète de "Sarpédonios " ${ }^{10}$, tandis que sa jumelle Artémis est qualifiée de "Sarpédonia " par Strabon ${ }^{11}$. Cette épiclèse évoquant le héros Sarpédon n'est attestée qu'en Cilicie et les sources à disposition font apparaître une personnalité divine originale, fruit des influences successives dont elle a fait l'objet et à travers lesquelles peuvent se lire les différents apports culturels qui ont touché cette région au carrefour des cultures.

5 Ainsi, notre étude tentera de décrypter cette divinité locale sur le temps long à la lumière de son contexte historique et culturel. Dans le même temps, nous tenterons d'apporter, par le prisme de l'histoire religieuse, des éléments nouveaux sur l'histoire culturelle de la région de Séleucie.

\section{Le héros Sarpédon}

D’après son épiclèse, Apollon est associé à Séleucie au héros Sarpédon dont la vie et les exploits nous sont rapportés par des sources de provenances diverses ${ }^{12}$. Fils de Zeus et de Laodamie, il est dans l'Iliade le chef des Lyciens, alliés des Troyens. Il tombe devant Troie sous les coups de Patrocle et son corps est rapatrié dans sa Lycie natale par Hypnos et Thanatos pour y être inhumé près du "Xanthe tourbillonnant $»^{13}$. Une autre tradition, relatée notamment par Hérodote ou Apollodore et déjà connue d'Hésiode ${ }^{14}$, mentionne un Sarpédon crétois, fils de Zeus et d'Europe, frère de Rhadamante et de Minos, qui à la suite d'un conflit avec ce dernier aurait fui la Crète pour l'Asie Mineure avec ses compagnons, avant de s'établir en Lycie et d'en devenir le roi grâce au soutien de son oncle maternel Cilix, roi de Cilicie. Sarpédon, frère de Minos, ne pouvait être contemporain de la guerre de Troie, puisque les Crétois y étaient commandés d'après Homère par Idoménée, petit-fils de Minos. Certains auteurs ont donc tenté de concilier les deux traditions en faisant du héros tombé sous les murs d'Ilion le petit-fils du Sarpédon crétois $^{15}$, tandis que d'autres accordent à ce dernier une durée de vie particulièrement longue ${ }^{16}$. Un troisième Sarpédon enfin, fils de Poséidon et frère de Poltys, serait originaire de Thrace $^{17}$ et l'on perçoit ainsi qu'il serait vain, comme le souligne $\mathrm{O}$. Casabonne à la suite de $\mathrm{F}$. Bron, « de vouloir réunir toutes ces données sur un seul personnage " pour « un nom qui se rencontre dès le deuxième millénaire dans l'Anatolie hittite ${ }^{18}$. 
7 Plusieurs explications ont été avancées sur l'étymologie de l'héronyme Sarpédon qui semble anatolien ${ }^{19}$. Pour E. Raimond, l'étymologie de Sarpédon admet deux hypothèses: "gišsarpa-, qui désigne un arbre (cyprès) ou un instrument aratoire + suffixe; sar(i)-pedan "plaine, lieu supérieur(e)" » et il en déduit que le héros serait « sans doute une divinité protectrice de la nature sauvage (

${ }^{d}$ LAMMA), à en juger par le lexique auquel appartiennent ses étymons $»^{20}$. On retrouve le terme nésite $\check{s} /$ sarpadans les tablettes cappadociennes et dans une inscription en hiéroglyphes hittites provenant de Karkémish où il est associé à la déesse Kubaba : Kubaba-sa+r-r-pa-s(a) (= Carch. A 4 c.). D'après E. Laroche, sarpa pourrait signifier selon les textes «majordome, notable, trésorier » ou « maire » ${ }^{21}$ et ${ }^{\mathrm{d} X}{ }^{\text {uru }}$ Sar-pa-en-ta (KBo II 1 III 20) désignerait le nom d'une ville hittite ou l'épithète d'une divinité2 ${ }^{2}$. O. Casabonne remarque toutefois que š/sarpaest hittite alors que Sarpédon est attaché à l'Anatolie méridionale, essentiellement louvite ${ }^{23}$. Quant à A. Tourraix, il rapproche du nom de Sarpédon un toponyme sa-ra-pe-da mentionné dans les tablettes de Pylos et reprend ainsi l'hypothèse de l'origine mycénienne du héros de l'Iliade, concédant toutefois que l'étymologie de son nom demeure obscure ${ }^{24}$.

\section{Le toponyme « Sarpédon » en Cilicie}

8 Si les différentes traditions se rapportant à Sarpédon concernent essentiellement la Crète et la Lycie, son nom apparaît dans certaines sources littéraires se rapportant à la Cilicie et plus spécifiquement à la région de Séleucie.

9 Sarpédon est premièrement le nom d'un promontoire ou d'un cap chez Strabon ${ }^{25}$ et Pline l'Ancien ${ }^{26}$, situé à quelques kilomètres à l'ouest de l'embouchure du Kalykadnos. C'est l'actuel İncekum Burnu, «la langue de terre qui ferme au sud le golfe de Taşucu » ${ }^{27}$ qui correspondrait au promontoire sablonneux où, selon Eschyle ${ }^{28}$, aurait été enterré le héros. Pomponius Mela en fait la limite du royaume d'un certain Sarpédon ${ }^{29}$, peutêtre le roi de Lycie évoqué par Hésiode ou Hérodote.

10 Chez Skylax ${ }^{30}$, deuxièmement, Sarpédon est le nom d'une cité à l'est de Holmoi. Le texte daterait du début du $v^{e}$ siècle av. J.-C. et serait la plus ancienne mention grecque du héros dans la région de la future Séleucie ${ }^{31}$. Il serait tentant de rapprocher le nom de la cité Sarpédon mentionnée par Skylax de la ville hittite uruSar-pa-en-ta (KBo II 1 III 20) comme le fait O. Casabonne en émettant toutefois l'importante réserve que la cité Sarpédon est en Cilicie et donc en milieu louvite et non hittite ${ }^{32}$. La cité est qualifiée de

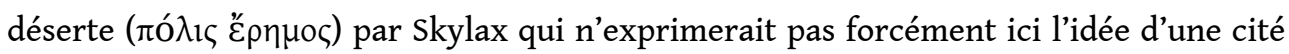
abandonnée mais plutôt celle d'une cité non grecque ou non perçue comme telle par le voyageur ${ }^{33}$. Il aurait par ailleurs pu confondre une polis avec le sanctuaire oraculaire dédié à un dieu Sarpédon ou qualifié de Sarpédonios mentionné par des sources plus tardives.

\section{L'oracle d'Apollon Sarpédonios}

11 «Sarpédonios » est l'épithète essentiellement portée par Apollon d'après Diodore ${ }^{34}$ et Zosime ${ }^{35}$. Tertullien ${ }^{36}$ évoque également un oracle de Sarpédon qu'il situe en Troade, mais aucune autre source ne vient confirmer l'existence de cet oracle oniromantique 
hors de Cilicie. Le témoignage de l'apologiste chrétien de Carthage a donc souvent été mis en doute. A. Bouché-Leclercq suggère notamment qu'il s'agit d'une erreur de Tertullien dont «l'érudition [...] n'est pas des plus sûres", en soulignant que "l'énumération des oracles qu'il cite en passant n'a pas besoin d'être bien exacte pour servir sa thèse $"^{37}$. Nous remarquerons également que le "Sarpedonis in Troade

» de Tertullien est cité entre les oracles ciliciens d'Amphilochos et de Mopsos et que l'auteur ou sa source a pu confondre la Cilicie du sud anatolien avec la Cilicie de Troade évoquée par Strabon ou Pline ${ }^{38}$. Quant à Artémis "Sarpédonia », elle n'est mentionnée elle aussi qu'une fois dans la documentation par le seul Strabon ${ }^{39}$.

L'oracle d'Apollon Sarpédonios est premièrement mentionné par Diodore qui, faisant référence à un fragment conservé de Photios, relate la consultation de l'oracle cilicien par le roi séleucide Alexandre Balas. Le dieu lui avait répondu qu'il fallait se garder de visiter le lieu qui avait vu naître l'être double. Cet oracle qui parut d'abord très obscur s'expliqua facilement à la mort du roi à Abai, une cité d'Arabie où était né un hermaphrodite. Ce passage de l'historien grec, qui écrit au I ${ }^{\text {er }}$ siècle av. J.-C., attesterait donc de l'existence du sanctuaire oraculaire d'Apollon Sarpédonios au milieu du II $^{\mathrm{e}}$ siècle av. J.-C.

L'oracle d'Apollon est encore actif près de quatre siècles plus tard et conserve son prestige en Orient si l'on en croit un passage de Zosime rapportant la consultation vers 270 ap. J.-C. de l'oracle sarpédonien par les Palmyréniens souhaitant savoir s'ils obtiendraient l'empire d'Orient. L'historien du ve siècle ap.J.-C. nous informe par ailleurs que le dieu « remettait à tous ceux qui pâtissaient du fléau des sauterelles, des séleuciades (il s'agit d'oiseaux qui vivent aux alentours du temple), qu'il les faisait emporter à ceux qui le demandaient, que ces oiseaux volaient avec les sauterelles, les attrapaient avec leur becs, dispersaient aussitôt leur masse innombrable, les détruisaient en un clin d'œil et libéraient les hommes de la calamité de ces bestioles ${ }^{40}$. Ce passage est très instructif sur la personnalité du dieu qui est la divinité majeure de Séleucie-du-Kalykadnos au moins depuis le $\mathrm{II}^{\mathrm{e}}$ siècle av. J.-C. si l'on s'en tient aux sources littéraires. Apollon Sarpédonios y apparaît essentiellement comme un dieu oraculaire renommé lié aux oiseaux, protecteur de la nature et des récoltes. On rapprochera en outre ce passage de Zosime, à la suite d'O. Casabonne ${ }^{41}$, de ce que nous apprend Pline l'Ancien des "séleucides", ces "oiseaux que les habitants du mont Cadmos, prient Jupiter de leur envoyer, lorsque les sauterelles dévastent leurs moissons $»^{42}$. Cicéron, qui a été gouverneur de Cilicie, souligne par ailleurs que "chez les Ciliciens, les Pisidiens et leurs voisins de Pamphylie (j'ai eu pour mission de gouverner ces peuples), c'est le vol des oiseaux et leurs cris qu'on juge être les signes révélateurs les plus sûrs de l'avenir $»^{43}$.

\section{Un dieu tutélaire anatolien}

Apollon Sarpédonios semble ainsi particulièrement proche de divinités tutélaires (logogramme ${ }^{\mathrm{d}}$ LAMMA) du $\mathrm{II}^{\mathrm{e}}$ millénaire qui sont le plus souvent spécifiées par une épithète parmi les populations louvites ${ }^{44}$. Le dieu aux oiseaux de Séleucie présente par exemple un certain nombre de similitudes avec "la divinité tutélaire au sac de chasse " ( ${ }^{\mathrm{L} L A M M A}{ }^{k u s ̌ k u r s ̌ a s ̌) ~ q u i ~ e s t ~ s o l l i c i t e ́ e ~ e n ~ c o n n e x i o n ~ a v e c ~ d e s ~ o i s e a u x ~ o r a c u l a i r e s ~ d a n s ~}$ certains rituels louvites de l'Arzawa des archives de Hुattuša ${ }^{45}$. En tant que maître de la 
nature sauvage, des animaux et des oiseaux, dLAMMA kuškuršaš est invoqué par les augures contre les mauvais présages qui ont été prédits par le vol des oiseau ${ }^{46}$.

Le dieu dLAMMA kuškuršaš, qui comme la plupart des divinités tutélaires doit être d'origine hattie ${ }^{47}$, est également invoqué dans des rituels contre l'impureté, la maladie, et notamment contre la peste. Le rituel CTH 433.2 est par exemple adressé au dLAMMA kuškuršaš, le dieu tutélaire aux oiseaux oraculaires et à son groupe des Sept démons. Ce rituel est notamment effectué par des augures pour que le dieu et les divinités furieuses, les Sept, puissent à nouveau être favorablement prédisposés envers le roi et sa famille ${ }^{48}$. Divinité provocant les maladies, il est ainsi invoqué contre celles-ci et devient alors un dieu protecteur et guérisseur.

M. Hutter, d'après les travaux de D. Bawanypeck, remarque que « the augur's rituals must be considered a special feature of Arzawan ritual practice $»^{49} . \mathrm{Il}$ semble toutefois qu'au moins un texte transcrivant les protocoles régissant l'observation des oiseaux (KBo 22.263)

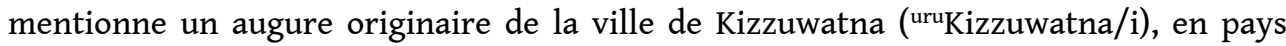
hourrito-louvite, ce qui tendrait à montrer que les rituels d'augures impliquant un dieu LAMMA ne sont pas exclusivement pratiqués dans l'Arzawa et pourraient tout à fait l'être dans la région de la future Séleucie ${ }^{50}$.

17 On conçoit donc aisément qu'un dieu oraculaire anatolien maître des oiseaux et de la peste ait pu être associé sur le territoire de Séleucie à l'Apollon grec, dieu oraculaire à la fois guérisseur et responsable des épidémies, ayant notamment le cygne pour attribut. Généralement nommé Kurunta puis Runtiyas/Runta dans les textes louvites ${ }^{51}$, le dieu LAMMA est le plus souvent représenté sur un cerf dont le signe, ou ses ramures, servent à le désigner dans les hiéroglyphes louvites ${ }^{52}$. Une scène d'offrande sur le col du rhyton à protomé de cerf couché de la collection Schimmel du Metropolitan Museum of $\mathrm{Art}^{53}$ le met en scène devant un fidèle offrant successivement une boisson, ce qui semble être du pain, puis une libation (Fig. 1). Le dieu-au-cerf est dressé sur son animal attribut et tient un oiseau dans la main gauche, un lituus dans la droite. Sur la gauche, deux lances plantées en terre séparent la scène d'une composition figurant un carquois, un sac de chasse et la dépouille d'un cerf au pied d'un arbre ${ }^{54}$. Dieu chasseur, Runtiyas est aussi archer, justifiant davantage son interpretatio grecque avec Apollon, bien qu'il semble être le plus souvent associé à Hermès en Cilicie, particulièrement dans la région de Korykos, voisine de Séleucie ${ }^{55}$. D'autres divinités grecques ont pu du reste être associées à Runtiyas en Cilicie, comme ce serait peut-être le cas d'Héraclès d'après une obole incertaine du IV siècle av. J.-C. par exemple, représentant au droit le portrait à la léontè du dieu juvénile de face, au revers un aigle sur une tête de cerf qui feraient explicitement référence au dieu Runtiyas (Fig. 2).

18 Apollon Sarpédonios figure sur un certain nombre de monnaies de Holmoi (Fig. 3-4) et de Séleucie (Fig. 5-6) du IV siècle av. J.-C. au III siècle ap. J.-C.56. Des références à cette divinité majeure de la région pourraient également figurer sur les rares sicles au nom $d^{\prime} U r a^{57}$ datés du milieu du $v^{e}$ siècle av. J.-C. qui représentent au droit ce qui semble être un cerf ou un animal cornu ${ }^{58}$, au revers, une chouette (Fig. 7). Les animaux attributs du grand dieu d'Ura et d'Athéna seraient ainsi représentés sur les sicles de la cité qui aurait précédé Séleucie ${ }^{59}$. Un statère unique portant la même légende araméenne ' $R H$ (Ura) que la monnaie précédemment décrite et datée elle aussi du milieu du $v^{e}$ siècle av. J.-C. représente plus clairement au droit un cerf à droite reconnaissable par sa ramure, au revers, les murs crénelés d'une cité comportant deux tours (Fig. 8). Ce statère viendrait confirmer là encore l'importance du dieu-au-cerf à Ura/Séleucie. De 
plus, si nous suivons la proposition d'O. Casabonne d'attribuer à la cité d'Ura les oboles anépigraphiques du IV ${ }^{e}$ siècle av. J.-C. figurant à l'avers la tête d'Athéna casquée à droite et au revers un dieu trônant imberbe tenant dans sa main un oiseau aux ailes déployées (Fig. 9), nous pourrions avoir sur ces monnaies, avec toute la prudence requise, la première représentation d'Apollon Sarpédonios lui-même.

\section{Un dieu lié à Athéna?} elle que s'oppose au $\mathrm{I}^{\mathrm{er}}$ siècle sainte Thècle qui voit en la déesse une rivale de choix ${ }^{6}$ La Vie et les Miracles de sainte Thècle, vraisemblablement composés au ve siècle de notre ère par un prêtre originaire de la région ${ }^{62}$, relatent comment la sainte s'est imposée à Séleucie au détriment des principales divinités païennes de la cité en accomplissant des miracles attribués jusqu'alors à celles-ci. Dès son arrivée à Séleucie, la sainte s'est par exemple installée sur le sommet de la montagne voisine sise au midi pour s'y dresser « comme un rempart contre le démon Sarpédon qui occupait le promontoire sur la mer, [...] comme un rempart contre la déesse guerrière de l'Acropole, Athéna...63 ». La sainte est également confrontée à Séleucie à d'autres divinités telles qu'Aphrodite ou Zeus mais elles ne sont évoquées dans le texte chrétien que de façon marginale et apparaissent ainsi comme des divinités de second rang

64 .

21 S'ils ont fait l'objet d'une intense reconstruction, ces récits hagiographiques nous informent toutefois sur les traditions locales qui transparaissent de la vie de la sainte et font apparaître une continuité des cultes locaux, continuité particulièrement évidente à l'époque tardive à laquelle ils ont été rédigés, dans un contexte de renaissance des cultes préhelléniques ${ }^{65}$.

Les épisodes relatifs aux prodiges accomplis par Thècle sont à ce titre particulièrement intéressants. Condamnée pour avoir refusé le mariage et voulu suivre l'enseignement de Paul, la sainte fut d'abord condamnée au bûcher mais le feu la protégea de la foule et elle fut sauvée par une tempête divine ${ }^{66}$. Elle fut ensuite une première fois jetée aux bêtes sauvages mais une lionne l'épargna puis la défendit jusqu'à la mort d'une ourse et d'un lion lors de sa seconde condamnation. Ces supplices ayant échoué, elle fut ensuite jetée, d'après la tradition, dans une fosse remplie de serpents avant qu'un globe de feu ne vienne la sauver en tuant tous les reptiles ${ }^{67}$. Ces récits chrétiens tardifs trouvent un certain écho dans ce que les sources païennes laissent percevoir des déesses locales et notamment d'Athéna en Cilicie. À Séleucie en particulier, la déesse est représentée sur des monnaies des II $^{\mathrm{e}}$ et $\mathrm{III}^{\mathrm{e}}$ siècles ap. J.-C. terrassant des géants anguipèdes (Fig. 10a-b) et l'on pourrait aisément faire le parallèle avec la victoire de Thècle sur les reptiles lors de son supplice. D'autres passages de la vie de la sainte témoignent de liens particuliers avec le culte d'Athéna à Séleucie et sa région. Thècle aurait en effet fini ses jours dans la grotte de Meriamlik, à l'extérieur de la cité, où elle faisait ses guérisons et aurait été ensevelie dans le rocher même. La grotte aménagée peut-être dès la fin $\mathrm{du}_{\mathrm{IV}}^{\mathrm{e}}$ siècle en basilique était au cœur d'un imposant centre cultuel comprenant notamment de nombreux bains et citernes ${ }^{68}$. Elle aurait pu servir de sanctuaire à une divinité 
préchrétienne et l'on pensera immédiatement à la déesse Athéna particulièrement honorée sur le territoire rural de Séleucie et ses environs dans un certain nombre de grottes aménagées en lieux de culte comportant parfois des bassins d'eau probablement utilisés dans un but thérapeutique ${ }^{69}$. Ces grottes et ces réservoirs donnent au culte d'Athéna $\ll a$ distinctly Anatolian flavour ${ }^{70}$ » comme le souligne T. Mitford qui suggère ainsi une origine préhellénique très ancienne au culte grécisé d'Athéna dans la région.

Celle-ci y est parfois qualifiée d'Oreia et semble donc liée à la montagne, au rocher ${ }^{71}$ comme notamment à Sömek, à une trentaine de kilomètres au nord-est de Silifke, où un relief gravé dans la roche la représente tenant un bouclier et une lance autour de laquelle s'enroule un serpent (Fig. 11) ${ }^{72}$. Une deuxième épiclèse Krisoa, souvent associée à la précédente et dont l'étymologie serait louvite, accentuerait son caractère martial et protecteur car l'épithète aurait une signification militaire comme probablement le nom de la forteresse Kiršu (act. Meydancıkkale) ${ }^{73}$ qui, au milieu du vi siècle av. J.-C., est avec Ura l'une des deux villes royales des dynastes de Pirindu, dont le royaume correspondrait environ à la région de Cilicie Trachée des auteurs grecs ${ }^{74}$. On retrouve également cet aspect guerrier/protecteur dans les miracles de sainte Thècle protégeant des cités ciliciennes contre leurs assaillants. À Séleucie par exemple, la martyre repousse une attaque surprise, «rien qu'en apparaissant au sommet des murailles, en lançant des éclairs et en poussant [...] le cri de guerre contre les ennemis... ${ }^{75} »$.

24 La déesse du relief de Sömek (Fig.11) présente également des aspects célestes symbolisés sur le pilastre à sa gauche par un croissant de lune, une étoile et un foudre ${ }^{76}$ évoquant des monnaies de Mallos figurant Athéna Magarsia avec une étoile de chaque côté de sa tête, tenant une lance et vêtue d'une robe de serpents ${ }^{77}$. Les Miracles de la sainte offrent là encore des parallèles intéressants lorsque Thècle, après un prodige, s'envole « comme une colombe " $^{78}$ »ou lorsqu'on la voit « haut dans les airs, montée sur un char de feu qu'elle conduit ${ }^{79}$ ».

25 En outre, la sainte est protégée par un fauve lors de son supplice et c'est sur un lion qu'Athéna est représentée sur des monnaies de Tarse du III siècle ap. J.-C., apparaissant comme une Potnia Therôn, une maîtresse des animaux sauvages, loin des conceptions canoniques de la déesse grecque (Fig. 12a). De même, une divinité guerrière brandissant un glaive et chevauchant un lion figurée au tournant du ${ }_{\mathrm{III}}^{\mathrm{e}}$ siècle ap. J.-C. sur des monnaies de la cité d'Isaura en amont du Kalykadnos (Fig. 12b), trouvent un parallèle à la fois avec l'Athéna de Tarse et la jeune Thècle défendue par une lionne.

La sainte maîtrisant le feu rappelle également ce que Strabon nous apprend du culte de la grande déesse de Castabala en Cilicie Plane, Artémis Pérasia, qui semble elle aussi fortement liée au feu ${ }^{80}$. Le géographe grec nous précise en effet que le temple de la déesse est desservi par des prêtresses marchant pieds nus sur des charbons ardents sans éprouver la moindre douleur.

À travers les récits sur sa vie, sainte Thècle semble donc apparaître comme l'avatar chrétien d'une divinité païenne préhellénique, maitresse de la nature sauvage à la fois sombre et protectrice présentant des aspects chthoniens et guérisseurs. G. Dagron met toutefois en garde contre une interprétation trop hâtive qui consisterait à voir seulement dans Thècle une Athéna chrétienne et à « considérer trop vite comme un transfert réel ce qui est en partie le fait d'un auteur trop enthousiaste et prisonnier d'une culture qui n'est pas chrétienne, même si sa foi l'est " ${ }^{81}$. Certes, Athéna garde à travers la sainte une allure très littéraire dans la Vie et les 
Miracles de sainte Thècle, lorsque le parallèle avec l'Athéna grecque de l'acropole protectrice de la cité est évident. Le texte laisse cependant transparaître tout autant des éléments se rapportant davantage à une Athéna cilicienne, loin de toute référence littéraire hellénique, dont les plus frappants sont peut-être le sanctuaire extra-muros de la grotte et les bassins d'eau à vocation thérapeutique.

Il est vrai qu'il est difficile de savoir si les récits relatifs à Thècle, tardifs et fortement reconstruits, doivent être rattachés précisément à une divinité païenne de Séleucie, où la sainte a vécu la dernière partie de sa vie et à laquelle son nom reste attaché, ou à une autre déesse locale similaire, déesse d'Iconium par exemple où la sainte a vécu ses supplices. Les aspects que nous avons évoqués se rattachant à une éventuelle déesse préhellénique se retrouvent cependant dans l'Ištar babylonienne, à l'origine déesse érotique et déesse guerrière ayant le lion pour attribut mais qui a été adaptée chez les Hourrites en Šauška en soulignant principalement le caractère guerrier de la déesse ${ }^{82}$. Particulièrement populaire en Cilicie et dans le sud-est anatolien au $\mathrm{II}^{\mathrm{e}}$ millénaire, le culte d'Ištar/Šauška avait pour centre le Kizzuwatna dont la capitale Kummanni semble devoir être identifiée comme la cité de Castabala en Cilicie orientale ${ }^{83}$.

À la suite de R. Lebrun qui voit dans l'Artémis Pérasia de la période gréco-asianique la continuité d'un culte local de la déesse babylonienne Ištar et de son interpretatio hourrite Šauška ${ }^{84}$, nous verrions en Thècle l'héritière chrétienne d'une divinité similaire, via son habillage grec en Athéna dans la région de Séleucie ${ }^{85}$ et probablement associée à l'Išstar/Šauška au II ${ }^{\mathrm{e}}$ millénaire ${ }^{86}$.

Dans la cité trachéote, Athéna partage en effet de nombreux points communs avec Ištar/Šauška. D'après les monnaies de la cité, elle apparaît comme la déesse poliade de Séleucie, une guerrière violente promachos et destructrice des géants (Fig. 10a-b), dont on situe le sanctuaire sur l'acropole de Séleucie à l'emplacement de la forteresse byzantine et qui aurait pu servir de "pôle urbanisateur" autour duquel se serait organisé le tissu urbain de la future Séleucie ${ }^{87}$. C'est une déesse sombre qui à l'époque de sainte Thècle, "à la manière d'un vautour, continue peut-être d'occuper la forteresse qui porte son nom, appelle de ses cris aigus les tisserands et petites gens bavards qui habitent autour, et secoue sa noire égide bordée de frange...88 ». Cet aspect sombre pourrait ainsi expliquer la terreur qu'inspire sainte Thècle à ses ennemis. «Les colères de Thècle font peur : elle a les gestes, les regards, les mots de la fureur la plus "noire" pour chasser les fossoyeurs de son église [...] (Mir. 30); elle n'est guère rassurante lorsqu'elle "arpente la ville en claquant des mains" pour annoncer qu'elle se vengera de Marianos

$\left(\right.$ Mir. 29) ${ }^{89}$.

» Elle n'hésite pas de plus à faire égorger des brigands ayant pillé son temple en les offrant « aux soldats pour un massacre tout préparé » 90.

Cette association d'Ištar/Šauška et de la déesse d'Ura/Séleucie grécisée en Athéna probablement à partir de l'époque perse, viendrait éclairer le lien très étroit qui l'unit au grand dieu de la région que l'on peut observer probablement sur les monnaies d'Ura, mais surtout sur celles de Holmoi et de Séleucie au moins jusqu'au début de l'époque romaine. Cette proximité du dieu d'Ura/Séleucie et d'Athéna sur les monnaies trouve en effet un parallèle avec les liens qui unissent la déesse Ištar et le dieu-au-cerf dans certains rituels du II millénaire d'influence hourrite dans lesquels ils sont invoqués ensemble. Dans le Rituel du dieu de l'orage de Kuliwišna, il reçoit par exemple des 
offrandes conjointement avec Ištar de la Campagne ${ }^{91}$ de même qu'il est honoré au Festival d'Ištar de ŠamuHa ${ }^{92}$. Pour F. Woudhuizen, les textes hiéroglyphiques de Yalburt et d'Emirgazi font apparaître la déesse Šauška comme l'épouse du dieu-au-cerf Kurunta et c'est également elle qui figure sur le rhyton de Schimmel aux côtés de Kurunta d'après la lecture qu'il fait de l'inscription associée à la déesse (Fig. 1) ${ }^{93}$. Cette étroite proximité liant les deux divinités pourrait du reste se retrouver dans la cité voisine de Soloi où, d'après Quinte Curce, Alexandre aurait organisé des jeux en l'honneur de Minerve et du dieu médecin Esculape qui pourrait lui aussi être l'interpretatio graeca d'une divinité tutélaire ancienne du même type. Le conquérant comme à son habitude pourrait honorer à Soloi les cultes locaux et perpétuer un ancien festival en l'honneur des deux divinités, à moins qu'il n'ait offert un sacrifice à Esculape/Asclépios pour le remercier de sa guérison après avoir contracté une maladie quelques jours plus tôt en se baignant dans les eaux du Kydnos ${ }^{94}$. De même, la cité pamphylienne de Sidé, proche de la Cilicie, comprend deux temples jumeaux d'Apollon et d'Athéna qui dominent le port. Les monnaies de la cité représentent très fréquemment la déesse guerrière associée au serpent et le dieu de la mantique avec arc et oiseau.

\section{Un dieu anatolien associé au dieu syro-phénicien Resheph} phéniciens de Karatepe, à l'est de la Cilicie, fait mention du dieu Runtiyas. Celui-ci est l'une des deux divinités tutélaires du commanditaire de l'inscription Azatiwada et son équivalent dans la version phénicienne de l'inscription est Resheph-Siprm ${ }^{95}$. F. Bron a rapproché l'épithète Siprm de l'hébreu Sippôr, signifiant « oiseau » en avançant un certain nombre d'arguments dont nous ne rapporterons pas le détail ici ${ }^{96}$. O. Casabonne, reprenant l'analyse de F. Bron, a alors rapproché la lecture Resheph « aux-oiseaux » mentionné à Karatepe, du dieu Apollon Sarpédonios de Séleucie dont il pressentait l'association avec le dieu louvite Runtiyas souvent représenté avec un oiseau ${ }^{97}$. Une deuxième interprétation de Sprm traduit l'épithète par «bouc » par rapprochement avec le terme hébreu Sâpir.Cette traduction, la plus communément admise, est celle que privilégie E. Lipinski qui remarque que «vu que l'inscription en pseudo-hiéroglyphes louvites assimile Resheph au dieu protecteur Runta, dont le cerf est l'animal sacré, et que la tête de gazelle est le signe distinctif de Resheph dans l'iconographie égyptienne, la détermination Sprm doit se rapporter à des animaux cornus, en hébreu "boucs", et point à des "oiseaux" ou à un toponyme de Cilicie ${ }^{98}$. 
légende araméenne ' $R H$ (Ura) et datées également du milieu du v siècle av. J.-C. d'après des critères paléographiques ${ }^{99}$, représentent cependant un bouc ou un bouquetin. A. Lemaire a étudié un monnayage de six sicles ciliciens au nom d'Ura ${ }^{100}$ comportant au revers une chouette; au droit un bouc agenouillé, parfois ailé, qui sur certains sicles porte sur sa croupe un oiseau à gauche, les ailes décollées et becquetant la croupe du capriné $^{101}$. L'association de l'oiseau et du bouc pourrait ainsi correspondre à la combinaison cerf/aigle de certaines monnaies ciliciennes plus tardive (Fig.2) et constitueraient une évocation "à la phénicienne» du dieu louvite au cerf souvent représenté avec un oiseau ${ }^{102}$. Un tel principe iconographique consistant à figurer une même divinité ou des références à celle-ci selon différents canons culturels semble également en application à la même période sur les monnaies de Tarse par exemple. Sanda, le grand dieu de la cité, serait en effet représenté aussi bien sous les traits du sémitique Nergal, que sous la forme du grec Héraclès ${ }^{103}$. Comme à Tarse, les monnaies d'Ura, de Holmoi et de Séleucie témoigneraient donc d'un phénomène d'interpretatio : les animaux attributs du dieu de la région d'Ura/Séleucie, oiseau/cerf, à la louvite, ou oiseau/bouc, à la phénicienne, auraient progressivement disparu dans l'iconographie monétaire d'Ura pour aboutir sur les monnaies de Holmoi et de Séleucie à une représentation canonique de l'Apollon grec auquel le dieu a été associé104.

Des influences sémitiques intenses et anciennes dans la région d'Ura/Séleucie pourraient en outre expliquer une association du dieu louvite Runtiyas au dieu phénicien Resheph.

Dès la deuxième moitié du $\mathrm{II}^{\mathrm{e}}$ millénaire, le port d'Ura entretient avec la syrienne Ougarit un commerce florissant et ses marchands, «fils d'Ura », sont aux ordres du roi hittite. Ougarit, grand centre économique et religieux au II millénaire, n'est en effet qu'à environ 150 kilomètres d'Ura avec laquelle elle commerçait directement par bateaux. Dans le sillage de ces relations commerciales circulaient donc très certainement des échanges culturels et religieux entre ces deux régions. Des versions très similaires du mythe de Typhon se trouvent par exemple localisées au mont Kasios, à l'embouchure de l'Oronte tout près de l'ancienne Ougarit ainsi qu'à Korykos située à moins d'une vingtaine de kilomètres à l'est d'Ura/Séleucie. F. Vian souligne que le mythe, sur les bords de l'Oronte comme à Korykos, est lié à un phénomène hydrologique semblable d'eaux résurgentes. Pour lui, «l'emprunt est évident 105 ». Auv siècle ap. J.-C. encore, beaucoup d'habitants de la cité de Korykos montrent d'après leurs épitaphes une origine syrienne ${ }^{106}$. Peut-être est-ce là l'indice de la continuité d'antiques relations entre cette région de Cilicie Trachée et le monde levantin.

D'après E. Lipinski, c'est surtout dans les textes retrouvés à Ougarit et sur le site voisin de Rās Ibn Hani que l'on peut se faire une idée de la personnalité du dieu Resheph. "Désigné à différentes reprises au moyen du logogramme dLAMMA des divinités protectrices, il est en même temps un dieu belliqueux et redoutable, maître des fléaux décochés par son $\operatorname{arc}^{107}$ " au même titre que le louvite Runtiyas ou le grec Apollon ${ }^{108}$.

Mais c'est avant tout à Chypre, voisine d'Ura/Séleucie, que l'on rencontre les attestations de Resheph où son culte remonte au Bronze Récent et où il a été associé " avec un grand dieu local appelé Apollon en grec » ${ }^{109}$ qui apparait comme la principale divinité masculine de l'île à en juger par les textes et le nombre des témoignages épigraphiques ${ }^{110}$. Un culte de Resheph/Apollon est par exemple attesté dans la cité 
d'Idalion conjointement avec la grande déesse locale probablement guerrière et tutélaire, comme à Ura/Séleucie, qui est vénérée " tantôt comme Athéna, tantôt comme Anat, par une population métissée comprenant des Chypriotes, des Grecs et des Phéniciens " ${ }^{111}$. Étudiant la Red Lustrous Wheel-made Ware (RLW-m), E. Kozal a mis en lumière les connexions entre Chypre et la Cilicie Trachée au Bronze Récent, ainsi que l'importance de la vallée du Kalykadnos comme voie de pénétration et d'échanges avec le cœur de l'empire hittite ${ }^{112}$. Mythographes et historiens attestent également de liens étroits et anciens entre la Cilicie Trachée et Chypre où auraient par exemple été importés la science et l'art des haruspices par "Tamiras le Cilicien ${ }^{113}$. Certaines légendes témoigneraient aussi de liens entre les cultes d'Apollon tels qu'ils sont pratiqués en Cilicie et au sanctuaire d'Apollon Hylates à Kourion. Bien que donnant peu de crédit à l'événement, Strabon rapporte notamment qu'un troupeau de biches sacrées d'Apollon aurait traversé la mer depuis les cimes escarpées de Korykos, située à un peu plus d'une dizaine de kilomètres à l'est de Séleucie, pour chercher refuge à Kourion sur la côte sud de Chypre $^{114}$. Claude Élien évoque également des cerfs ayant trouvé asile dans l'enceinte sacrée d'Apollon à Kourion ${ }^{115}$. Ces passages se feraient ainsi l'écho de liens culturels entre ces deux régions où le cerf semble associé à Apollon ${ }^{116}$ et l'on pensera au dieu-au-cerf Runtiyas qui aurait précédé le dieu grec au moins dans la région de Séleucie. Des modes architecturales funéraires similaires dans les deux régions aux $\mathrm{VII}^{\mathrm{e}}$ et $\mathrm{VI}^{\mathrm{e}}$ siècles av. J.-C. suggèrent aussi des liens culturels entre la Cilicie et Chypre et l'on pourra rajouter à ces exemples qu'une cité de Soloi est attestée à Chypre comme en Cilicie, que le syllabaire chypriote grec est utilisé en Cilicie et que «le Cilicien » est un surnom bien connu à Chypre ${ }^{117}$.

\section{Le dieu Apollon}

Runtiyas est le plus souvent associé à Hermès en Cilicie mais c'est bien Apollon qui s'est imposé dans la région de Séleucie, probablement parce que les fonctions oraculaires du dieu devaient être prédominantes, comme en attestent les passages de Diodore et de Zosime évoqués plus haut.

41 La protection que le dieu offre contre le fléau des sauterelles pourrait également expliquer cette association avec le dieu solaire grec, même si le lien ne paraît pas évident de prime abord. Le comportement des nuages de sauterelles est en effet rythmé par le soleil et c'est à la tombée de la nuit que les essaims descendent au sol pour s'abattre sur les récoltes et tout dévorer, avant de repartir le lendemain au lever du soleil ${ }^{118}$. Apollon, dieu solaire, devait donc être perçu comme un protecteur contre ces insectes qui détruisent tout sur leur passage dès qu'il disparaît. De même, les aptitudes médicales du dieu devaient entrer en jeu au moment des invasions de sauterelles qui infestent les sources, les puits et les rives des fleuves et sont la cause de maladies contagieuses $^{119}$. Cette fonction n'est du reste pas spécifique à l'Apollon Sarpédonios si l'on en croit Pausanias qui évoque l'Apollon Parnopios d'Athènes qui protège lui aussi contre les sauterelles ${ }^{120}$.

C'est vraisemblablement Apollon Sarpédonios qu'il faut en outre reconnaître sur des monnaies de Séleucie du II $^{\mathrm{e}}$ et $\mathrm{du}$ III $^{\mathrm{e}}$ siècle ap.J.-C. sur lesquelles apparaissent fréquemment une divinité radiée sur un cheval en marche, devant lequel se trouve un autel (Fig. 13 a). L'image apparaît pour la première fois sous Hadrien. Elle est ensuite reprise sous Geta puis figure sur les monnaies de la cité jusqu'au dernier quart du III 
siècle ap.J.-C. Cette représentation du dieu de Séleucie paraît quelque peu éloignée de l'image canonique de l'Apollon grec. Elle trouverait toutefois une explication dans le contexte de l'époque d'émission de ces monnaies puisque d'autres cités d'Asie Mineure figurent de la même manière leurs principales divinités masculines à la même période. Comme pour les représentations originales du Mithra cavalier sur les monnaies pontiques de Trapezus (Fig. 13b) à propos desquelles J. Dalaison et B. Rémy suggèrent, à la suite de N. Belayche, "une contamination, au moins iconographique, des représentations anatoliennes (ou thraco-anatoliennes) de dieux masculins cavaliers ${ }^{121}$ » tels qu'ils sont représentés en Lydie, en Lycie ou en Pisidie par exemple ${ }^{122}$, nous aurions à Séleucie une "contamination" similaire qui aurait gagné l'iconographie d'Apollon Sarpédonios. Seuls quelques attributs (ex. : labrys, massue, bonnet phrygien, couronne radiée...) permettent en effet de distinguer par exemple les dieux Sozon (Fig. 13c), Kakasbos ou parfois Mithra (Fig. 13b) dans les représentations monétaires de ces divinités lorsqu'elles montent un cheval. La couronne radiée du dieu de Séleucie affirmerait ici son aspect solaire et l'identifierait comme Apollon. Dans le contexte du III ${ }^{\mathrm{e}}$ siècle qui voit progressivement Sol s'affirmer comme la divinité principale de l'Empire ${ }^{123}$, l'attribut d'Apollon Sarpédonios devait prendre ainsi toute son importance à Séleucie qui voyait son dieu protecteur, le soleil divinisé, davantage légitimé. La couronne radiée du dieu devait également trouver un écho dans celle qu'arborent certaines figures impériales sur les monnaies de la cité au même moment (ex. Fig. 10b). Un dialogue complexe semble donc s'instaurer dans l'iconographie monétaire de Séleucie au III ${ }^{\mathrm{e}}$ siècle entre l'Empereur, son dieu protecteur Sol, et l'Apollon de Séleucie qui apparaît toujours comme le grand dieu de la cité et acquiert à cette époque un rayonnement particulier. Dans la même idée, le type monétaire représentant l'Athéna poliade présentant une Niké à Apollon Sarpédonios qui devient ainsi victorieux (Fig. 13d), devait non seulement affirmer le lien étroit qui unit les deux divinités depuis les origines de la cité, mais aussi entrer en résonance avec le Sol Invictus qui s'impose à l'époque partout dans l'Empire.

\section{Sarpédonios/Sarpédon à Séleucie-du-Kalykadnos}

Divinité protectrice probablement d'origine hattie ${ }^{124}$, le dieu de la région d'Ura/ Séleucie semble donc avoir été associé au dieu louvite Kurunta/Runtiyas puis au dieu syro-phénicien Resheph même s'il est délicat de proposer une chronologie ne serait-ce que relative, avant son association au grec Apollon. C'est un dieu principalement oraculaire et protecteur lié par certains aspects à la chasse et aux animaux sauvages. On retrouve tous ces aspects dans la personnalité des différents dieux auxquels il a été associé et à travers lesquels peuvent se lire les diverses influences culturelles qui ont touché la région de Séleucie.

L'héronyme Sarpédon est attesté dans la région d'Ura/Séleucie sur une période d'un millénaire environ depuis le passage probablement du début du ve siècle av. J.-C. de Skylax mentionnant la cité déserte Sarpédon ${ }^{125}$ et le $\delta \alpha i ́ \mu \omega \nu$ Sarpédon consulté par les habitants de Séleucie à l'époque de sainte Thècle. 
Certains points restent toutefois difficiles à expliquer car le double nom cultuel ${ }^{126}$ "Apollon Sarpédonios », qui désigne le dieu de Séleucie dans la majorité des sources, est lui-même quelque peu surprenant. Ce théonyme associe le nom d'une divinité panhellénique à une épiclèse évoquant le héros Sarpédon. Dans le système complexe de la construction du nom divin, l'épiclèse détermine le dieu et lui confère une nature particulière. Elle peut être de nature diverse : toponymique, topographique, fonctionnelle ou historique 127.

Le plus évident consisterait à penser que l'épiclèse "Sarpédonios" est historique : selon un processus bien connu par ailleurs, une divinité mineure originairement indépendante (Sarpédon) aurait été absorbée par une divinité majeure jouissant d'un plus grand prestige dans le monde grec (Apollon) et réduite au statut d'une épithète de celle-ci ${ }^{128}$. Sarpédon serait ainsi le nom ancien de la divinité de la région d'Ura/ Séleucie. Ce théonyme serait antérieur à " Apollon Sarpédonios ", soit la plus ancienne mention de ce dieu qui nous a été transmise dans sa version grecque par Diodore relatant une consultation de l'oracle au milieu du $\mathrm{II}^{\mathrm{e}}$ siècle av. J.-C. Au v viècle ap. J.-C., son nom tendrait à réapparaître. Le dieu mentionné dans les récits relatifs à sainte Thècle n'est en effet plus dénommé Apollon mais $\Sigma \alpha \rho \pi \eta \delta o ́ v 1 o \varsigma$, d'après l'épiclèse qualifiant précédemment le dieu grec, ou simplement $\Sigma \alpha \rho \pi \eta \delta \omega v^{129}$ et l'on constate donc que ses liens avec le grand dieu grec de la mantique tendent à s'estomper. Un passage des Miracles de sainte Thècle

témoignerait même d'une distanciation effective entre Sarpédon et Apollon à cette époque puisque l'hagiographe déclare, face à l'incrédulité d'un païen guéri par la sainte : «Puisse ton âme être guérie par la martyre, même si tu devais en attribuer la responsabilité à Sarpédon, à Apollon, ou au démon que tu voudras ${ }^{130}$.»

La coïncidence fonctionnelle qui explique le plus souvent ce type de construction théonymique double n'est pourtant pas flagrante entre Apollon et Sarpédon. On perçoit mal pourquoi un dieu oraculaire, guérisseur et chasseur porte une épiclèse évoquant un héros qui n'est pas connu dans la littérature pour ses pouvoirs iatriques ou ses aptitudes cynégétiques et contrairement à d'autres héros de la guerre de Troie faisant l'objet d'un culte oraculaire en Cilicie, tels les réputés devins Amphilocos et Mopsos, il ne présente aucun lien particulier avec la mantique. Un culte héroïque consacré à Sarpédon est par ailleurs attesté en Lycie et notamment à Xanthos où des jeux étaient organisés en son honneur encore à l'époque romaine ${ }^{131}$. Un dème de la cité y porte son nom de même qu'à Tlôs mais rien n'indique qu'il y ait fait l'objet d'un culte thérapeutique ou oraculaire ${ }^{132}$.

Il faut en outre souligner que le dieu honoré à Séleucie n'est pas "Apollon Sarpédon » mais bien «Apollon Sarpédonios » et ce type de théonyme double associant les noms de deux dieux ou héros masculins sous la forme d'un substantif («Apollon») et d'une forme adjectivale ( Sarpédonios») ne se rencontre guère dans le monde grec ${ }^{133}$. Pour expliquer cette forme originale, on pourrait avancer qu'on la rencontre dans un milieu culturellement mixte aux marges du monde grec où ce type de construction est parfois peu lisible. Comme dans d'autres cas du même type, l'épiclèse servirait ici « de butte témoin à une histoire dense et complexe, conjuguant selon un processus obscur le nom du dieu à celui de son prédécesseur $»^{134}$. Toutefois, le nom du dieu Sarpédon $(\Sigma \alpha \rho \pi \eta \delta \omega ́ v)$ à Séleucie n'est attesté seul que dans les textes hagiographiques tardifs 
relatifs à sainte Thècle dans lesquels il y est même parfois encore nommé «le Sarpédonien » $(\Sigma \alpha \rho \pi \eta \delta \delta \text { vioc })^{135}$. Cette identification avec le héros Sarpédon ne pourrait donc être que très tardive.

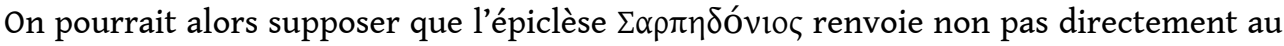
héros Sarpédon mais à un toponyme, éventuellement la cité mentionnée par Skylax ou le cap qui porte son nom: le dieu serait ainsi l' «Apollon de Sarpédon », le dieu « de Sarpédon ». Cette hypothèse paraîtrait plus logique qu'un théonyme composite inédit formé par l'association de deux divinités présentant peu de similitudes.

Quelques autres toponymes relatifs à Sarpédon sont connus hors de $\mathrm{Cilicie}^{136}$. On connaît en particulier une île « $\Sigma \alpha \rho \pi \eta \delta o v i ́ \alpha »$ mentionnée par Stésichore ${ }^{137}$ au vI ${ }^{\mathrm{e}}$ av. J.C. et deux siècles plus tard par Palaiphatos ${ }^{138}$ située dans l'archipel des Purpuraires au large de l'actuelle Essaouira. L'archipel et principalement sa plus grande île Mogador, étaient une colonie phénico-punique vraisemblablement liée au commerce de l'or ${ }^{139}$. Un abondant matériel épigraphique y a été mis au jour, le plus riche et le plus varié de tout le corpus épigraphique phénico-punique du Maroc, essentiellement constitué d'ostraca gravés à la pointe sur fragments de plats ou d'amphores ${ }^{140}$. Datés probablement du vil ${ }^{\mathrm{e}}$ siècle av. J.-C., ces tessons sont d'un intérêt remarquable du point de vue de l'histoire des religions puisque certains portent quelques théophores composés sur le nom du grand dieu de Sidon Eshmun, constituant ainsi les plus anciennes mentions épigraphiques indirectes du dieu très rarement attestées avant le $\mathrm{vI}^{\mathrm{e}}$ siècle dans les sources phéniciennes ${ }^{141}$. Un autre anthroponyme, vraisemblablement composé sur le nom de la déesse Tanit, constituerait en outre la première mention de la future grande déesse de Carthage qui n'est attestée en Phénicie que par une seule dédicace à « TanitAstarté " gravée sur une plaque en ivoire et datée probablement de la toute fin du VII siècle qui a été mise au jour dans la ville sidonienne de Sarepta ${ }^{142}$. À la suite de P. Xella, " on ne peut pas échapper à l'impression donnée par les théophores d'Eshmun et de Tanit qui ne suggèrent pas seulement une origine phénicienne des graveurs, mais nous semblent aussi orienter (avec toute la prudence requise) vers l'aire culturelle sidonienne ${ }^{143}$

». On pourrait même penser que ceux-ci étaient plus particulièrement liés à la cité de Sarepta, dépendance sidonienne située sur la côte levantine à mi-chemin entre Sidon et Tyr, si l'on se fie aux références à la fois à Eshmun et à Tanit attestés ensemble en Phénicie uniquement à Sarepta jusqu'à présent ${ }^{144}$. Le nom même de l'île "Sarpédonia » pourrait également suggérer un lien avec la cité de Sarepta puisque ces deux toponymes paraissent particulièrement proches. Le nom de la ville phénicienne, peut-être mentionné dès le III millénaire notamment dans un document administratif d'Ebla $\left(S a-a r-p a ́\right.$-at ${ }^{\mathrm{ki}}$, en phénicien $S \mathrm{r}^{145}$, rappelle en effet fortement "Sarpédon ». Le nom "Sarpédonia », qui nous est transmis par un auteur grec, découle probablement du nom phénicien de cette île culturellement proche de Sarepta. Peut-être rappelait-il le nom d'une éventuelle métropole et aurait évoqué le nom du héros de l'Iliade à l'auteur ou à quelques voyageurs grecs avant lui qui l'auraient restitué par euphonie en "Sarpédonia ", selon leur cadre culturel hellénique de référence. Si nous poussons davantage l'hypothèse en faisant un parallèle phonétique et sémantique avec les noms grec et phénicien de la cité de Carthage

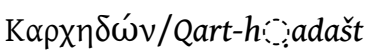

(« ville nouvelle »), nous pourrions en outre penser que le toponyme « $\Sigma \alpha \rho \pi \eta \delta \omega ́ v ~ »$ découle du phénicien 
S. rpt-hadašt qui signifierait «nouvelle Sarepta $»^{146}$. Ainsi, faudrait-il voir dans la cité de Sarpédon évoquée par Skylax à l'est de Holmoi en Cilicie ${ }^{147}$, une " nouvelle Sarepta ", un éventuel comptoir commercial phénicien établi près de l'embouchure du Kalykadnos qui présente un intérêt stratégique indéniable? L'hypothèse est certes conjecturale mais plusieurs éléments pourraient inciter à poursuivre dans ce sens.

Le héros Sarpédon lui-même pourrait en effet être lié à Sarepta. Nous avons vu plus haut les différentes légendes attribuant au héros Sarpédon soit une origine lycienne, soit une origine crétoise. Les Miracles de sainte Thècle rapportent toutefois une version cilicienne du mythe de Sarpédon qui tendrait à attribuer au dieu une origine phénicienne ${ }^{148}$ :

Il n'est personne qui ne connaisse notre Sarpèdonios : très ancienne est la légende qui le concerne et que nous ont apprise récits et livres. Certains savent même parce qu'ils ont le tort d'être encore impies, mais comme on peut l'être de génération en génération - que cet homme fut jadis un étranger, venu loin de chez lui, errant à la recherche de sa sœur et déposé par la mer sur les côtes de ce pays; ils savent que, ne connaissant pas les lieux et ignorant qui régnait alors (c'était Kilix, son oncle, le frère de son père), il fut mis à mort pour avoir causé quelque dommage aux gens du cru et s'être attiré leur hostilité, et fut enterré sur cette avancée au bord de la mer.

Par l'allusion au rapt d'Europe par Zeus que sous-entend l'errance de Sarpédonios mentionnée ici, la version locale du mythe que nous relate l'hagiographe se rattache à la tradition conférant une origine crétoise au héros de l'Iliade ${ }^{149}$. Cependant, ce passage rappelle fortement l'épisode rapporté notamment par Apollodore qui fait de Kilix et non de Sarpédon comme ici, le frère d'Europe parti à la recherche de sa sœur ${ }^{150}$. En considérant Sarpédon comme le frère d'Europe fille d'Agénor, roi de Phénicie, la tradition cilicienne tendrait donc à attribuer à Sarpédon une origine phénicienne, même si l'épisode relaté par l'hagiographe de sainte Thècle n'évoque qu'un « étranger, venu loin de chez lui ».

53 La fille d'Agénor passe dans les versions les plus courantes pour une princesse sidonienne et Lucien de Samosate rapporte même que le temple sidonien dédié à Astarté était en fait consacré à Europe ${ }^{151}$. L'enlèvement d'Europe est du reste très fréquemment représenté sur les monnaies de Sidon (Fig. 14a) pendant près de cinq siècles ( $\mathrm{II}^{\mathrm{e}}$ s. av. J.C. - $\mathrm{III}^{\mathrm{e}} \mathrm{s}$. ap. J.-C.) et l'on retrouve aux $\mathrm{II}^{\mathrm{e}}$ et $\mathrm{III}^{\mathrm{e}}$ siècles ap. J.-C. à Séleucie des types monétaires très semblables (Fig. 14b) qui illustrent ainsi l'ancrage local du mythe de Sarpédon et son rattachement à la tradition phénicienne.

Mais d'après le poète grec du Iv siècle av. J.-C. Lycophron, Europe est plus précisément originaire de la ville sidonienne de Sarepta et c'est sur les plages de cette cité qu'elle aurait été enlevée par Zeus ${ }^{152}$. Dépendance de Sidon d'après la Bible ${ }^{153}$, la cité de Sarepta, à mi-chemin entre Sidon et Tyr, est à l'époque impériale sous contrôle tyrien ${ }^{154} \mathrm{ce}$ qui pourrait expliquer que les Anciens aient parfois donné comme cadre au mythe d'Europe la cité de Tyr. S'il est bien évidemment délicat d'accorder une réalité historique aux mythes relatifs à Europe et Sarpédon qui ont fait l'objet de maintes recompositions en fonction des objectifs de leurs auteurs, cette version locale du mythe du Sarpédonien ( $\Sigma \alpha \rho \pi \eta \delta o ́ v 1 o \zeta)$, frère d'Europe, garderait peut-être le souvenir d'un lien entre ce dieu topique et la Phénicie, voire Sarepta. Cet « étranger, venu loin de chez lui, [...] et déposé par la mer sur les côtes de ce pays » pourrait-il rappeler la mémoire de marins sidoniens/sarepténiens venus s'établir à Sarpédon, la cité déserte mentionnée par Skylax ou le cap du même nom, comme l'ont fait d'autres phéniciens ailleurs en 
Cilicie $^{155}$

? La mise à mort du dieu « pour avoir causé quelque dommage aux gens du cru et s'être attiré leur hostilité » pourrait-elle évoquer le souvenir de rapports conflictuels entre ces phéniciens et les populations locales? Il est bien entendu difficile de conclure en

l'absence d'autres éléments. dédicace digraphe en grec alphabétique et syllabique mise au jour dans la cité, datée du $\mathrm{IV}^{\mathrm{e}}$ siècle av. J.-C. et dédiée par un Chypriote à Asclépios ${ }^{159}$. L'inscription y atteste à cette époque de l'existence d'un sanctuaire dédié à un dieu guérisseur dont la renommée

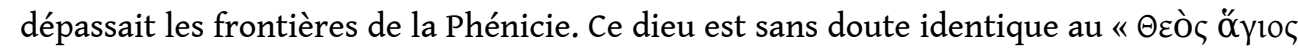
$\Sigma \alpha \rho \alpha \pi \tau \eta v o ́ \varsigma$ " connu par deux inscriptions grecques d'époque romaine provenant de Sarepta ainsi que deux bilingues gréco-latines du port de Pouzzoles en Italie. L'épithète " dieu saint », s'applique à diverses divinités orientales, mais sa qualification indique qu'il s'agit du dieu principal de Sarepta ${ }^{160}$. On se demande ainsi s'il ne pourrait pas y avoir quelque rapport, dont il est difficile de définir la nature, entre le dieu

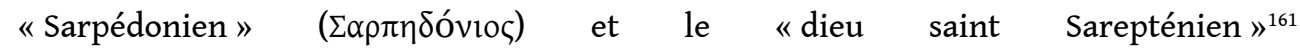
( $\Sigma \alpha \rho \alpha \pi \tau \eta v o ́ \varsigma)$, tous deux juvéniles et guérisseurs, qui d'un point de vue linguistique s'expliquerait aisément (métathèse arpe/arep; dentaled/t) à partir du phénicien $S$ irpt et que l'on pourrait facilement comprendre dans le passage aussi délicat d'une langue sémitique à la langue grecque aux sonorités très éloignées l'une de l'autre et difficiles à restituer.

Selon E. Lipinski, « deux divinités guérisseuses sémitiques entrent en ligne de compte à Sarepta: Eshmun, le grand dieu sidonien, et Shadrapha, qui est attesté à Sarepta même ${ }^{162}$ ». Ce sont deux dieux juvéniles protecteurs et guérisseurs qui ont été associés dans différents contextes à Apollon ou Asclépios. À Chypre par exemple, de nombreux théophores composés sur Eshmun sont attestés auxquels succéderont à l'époque hellénistique d'autres théophores formés sur Asclépios ${ }^{163}$. Dieu médecin comme Apollon, Eshmun semble également lié à la chasse, comme Runtiyas, Resheph et dans une certaine mesure l'archer Apollon, si l'on en croit Damascius qui décrit le dieu phénicien comme un chasseur "accoutumé à pratiquer la chasse dans ces vallées boisées $»^{164}$. Shadrapha est quant à lui attesté à Sarepta par une dédicace retrouvée sur 
un fragment de jarre du v $\mathrm{v}^{\mathrm{e}}-\mathrm{IV} \mathrm{e}^{\mathrm{e}}$ siècle av. J.-C. ${ }^{165}$. Son nom Šdrp'aurait le sens de « génie guérisseur » et il serait peut-être à Sarepta « une forme locale d'Eshmun, identique au "dieu saint" ${ }^{\prime 166}$

». Shadrapha serait également connu en Anatolie méridionale puisqu'il y est peut-être mentionné dans la trilingue de Xanthos, bien que la lecture du passage en araméen pose problème, et son équivalent dans la version grecque du texte serait Apollon 167.

Si l'on peut comprendre l'association Runtiyas/Resheph/Apollon, il est toutefois délicat d'appréhender à Séleucie Apollon Sarpédonios perçu, d'après les témoignages tardifs dont nous disposons, essentiellement comme un dieu médecin et qui pourrait peut-être avoir quelques liens avec des divinités elles aussi guérisseuses mais également chasseresses de la région de Sidon/Sarepta.

Comment expliquer en outre que le dieu anatolien d'Ura/Séleucie ait été associé à deux divinités syro-phéniciennes différentes, Resheph et Eshmun/Shadrapha? Deux pistes qui ne s'excluent pas l'une l'autre peuvent être envisagées.

61 Premièrement, Resheph et la divinité guérisseuse de Sidon/Sarepta pourraient être arrivés dans la région d'Ura/Séleucie à des périodes très éloignées l'une de l'autre. Resheph aurait pu gagner l'embouchure de l'actuel Göksu dès l'Âge du Bronze Récent depuis les régions où le dieu est honoré telles qu'Ougarit ou Chypre qui entretiennent d'étroites relations avec Ura dès cette époque ${ }^{168}$. Le dieu de Sarepta, quant à lui, se serait peut-être implanté dans la région à l'époque Néo-Assyrienne quand de fortes influences phéniciennes commencent à se faire sentir, voire plus tardivement encore, à l'époque achéménide par exemple quand des colonies phéniciennes sont attestées en Cilicie ${ }^{169}$.

Deuxièmement, il n'est pas exclu que ces deux divinités syro-phéniciennes aient été honorées ensemble à une période donnée. E. Puech dans son étude sur les dieux guérisseurs du sanctuaire d'Amrit/Marathos observe en effet que Resheph, Eshmun et Shadrapha notamment pouvait être vénérés dans un même complexe religieux ${ }^{170}$, même s'il regrette qu' « il n'est pas possible de se faire une idée quelque peu précise sur l'assimilation effective ou l'association de toutes ces figures divines, aux caractères somme toute très proches ${ }^{171}$. Peut-être que comme à Marathos, pérée d'Arados ellemême fondée par des exilés de Sidon d'après Strabon ${ }^{172}$, Ura/Séleucie aurait connu " une divinité polymorphe ou à plusieurs facettes, [...] toutes aux attributs de dieux guérisseurs $»^{173}$.

\section{Conclusion}

L'étude du dieu principal de Séleucie-du-Kalykadnos nous semble ainsi particulièrement révélatrice des processus religieux et culturels qui entrent en œuvre dans cette cité du sud-est de l'Asie Mineure et plus généralement en Cilicie. L'analyse historique de cette divinité sur le temps long fait apparaître les différentes strates culturelles qui se sont superposées et amalgamées dans la région.

Au terme de cette étude, on peut penser qu'Apollon Sarpédonios est probablement à l'origine une divinité tutélaire anatolienne locale fortement influencée par des traditions louvite, syro-phénicienne et grecque. Si l'on pense habituellement, et peutêtre dès l'Antiquité tardive, que le héros Sarpédon était honoré dans la région d'Ura/ 
Séleucie antérieurement à Apollon Sarpédonios, nous verrions plutôt dans l'épiclèse du dieu grec une indication toponymique se rapportant au cap Sarpédon ou à la cité évoquée au ve siècle av. J.-C. par Skylax située elle aussi à l'est de Holmoi.

Sur la base d'indices philologiques, historiques et religieux, nous pourrions en particulier émettre l'hypothèse, avec toutes les précautions d'usage, que la divinité principale de la région de l'embouchure du Kalykadnos classique témoignerait d'une présence phénicienne au Sud d'Ura/Séleucie où se serait implanté un éventuel comptoir phénicien fondé par des marchands de Sarepta. La position stratégique de la région aurait ainsi pu attirer ces commerçants dont la tradition locale aurait gardé le souvenir jusque dans les textes chrétiens tardifs évoquant un « étranger, venu loin de chez lui [...] déposé par la mer sur les côtes de ce pays ».

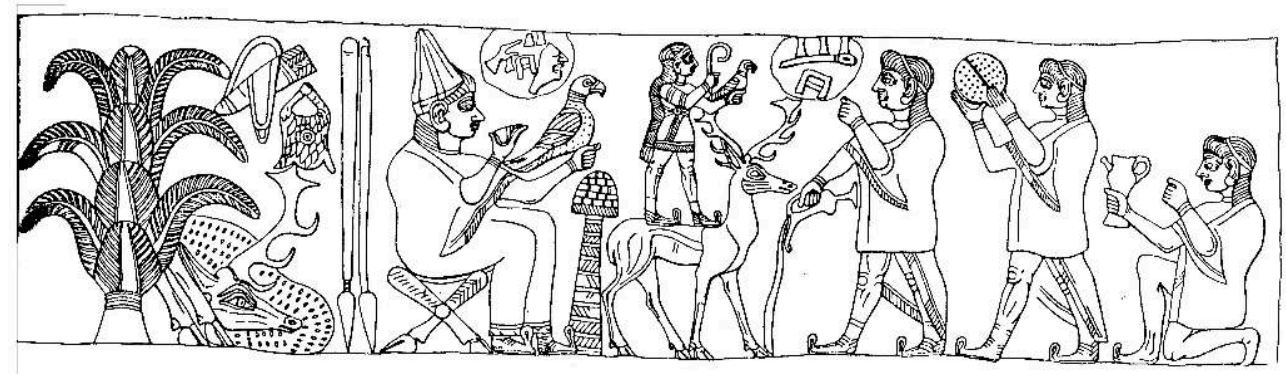

Fig. 1. Schéma de la scène rituelle d'un rhyton à protomé de cerf (Harper, Pittman [1987], p. 121).
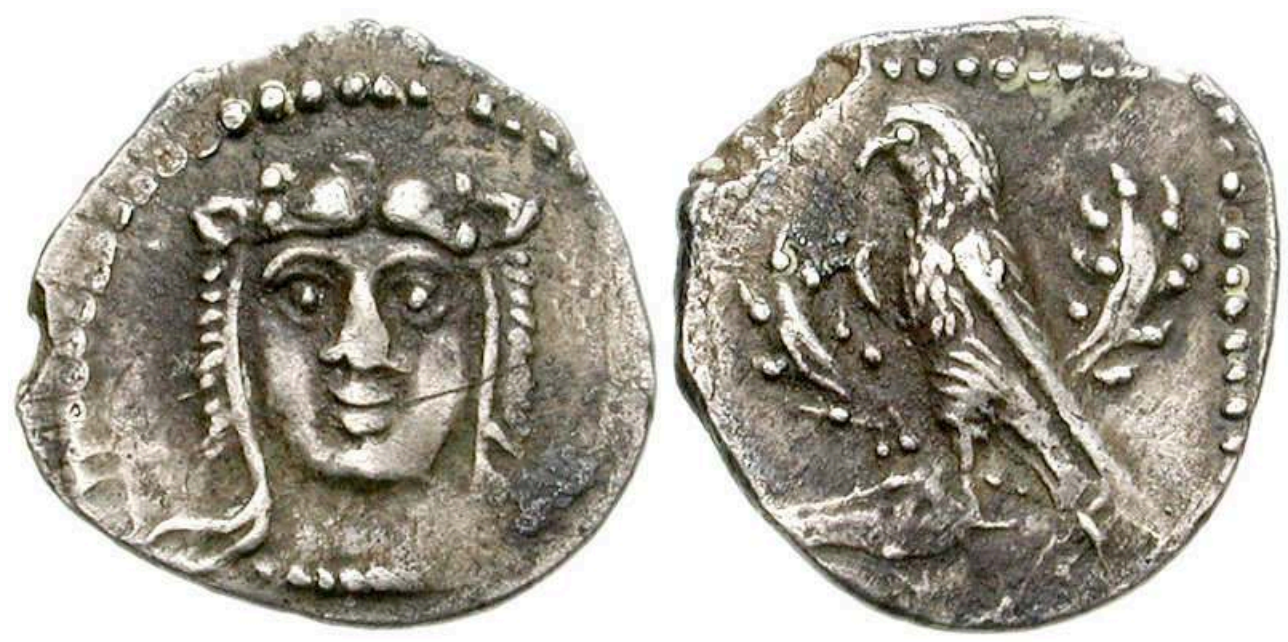

Fig. 2. Buste d'Héraclès (avers)/Aigle et tête de cerf (revers). Cilicie, Incertain, ıve s. av. J.-C. CNG 148, lot 207 (20 septembre 2006) - www.cngcoins.com.

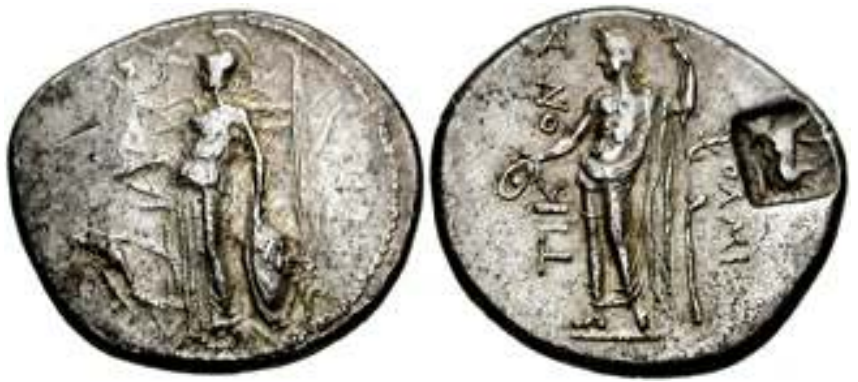

Fig. 3. Athéna (avers)/Apollon Sarpédonios (revers). Holmoi, ıve s. av. J.-C. Triton VII, lot 290 (12 janvier 2004) - www.cngcoins.com. 

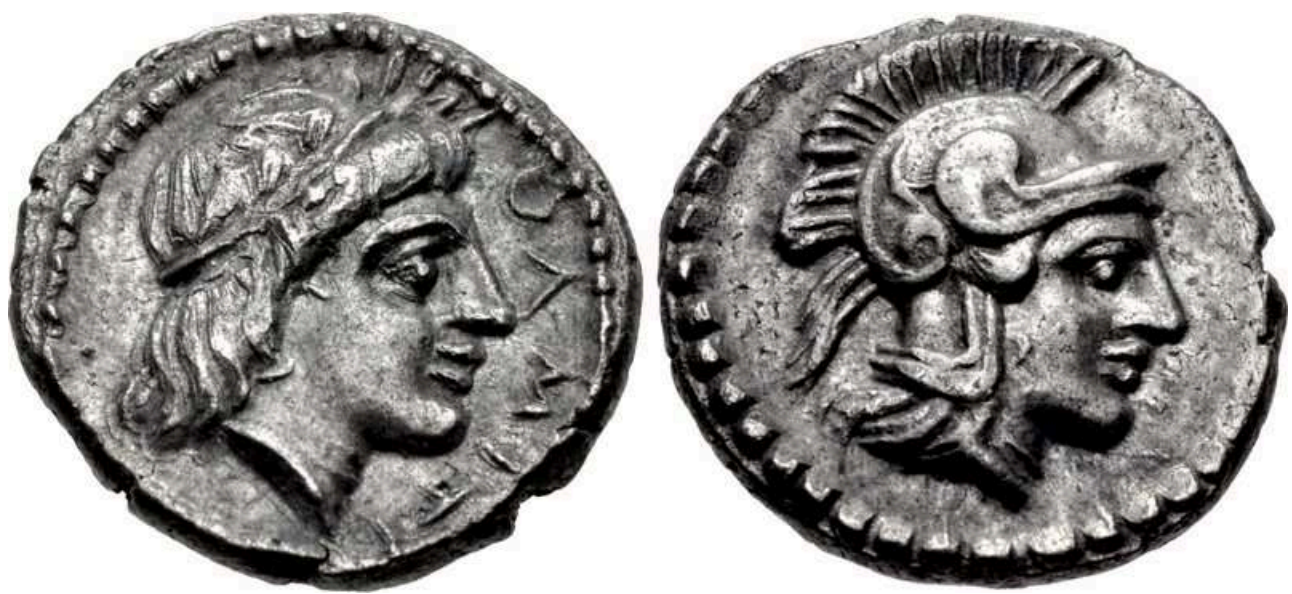

Fig. 4. Apollon Sarpédonios et Athéna. Holmoi, 380-375 av. J.-C.

Triton XVIII, lot 48 (5 janvier 2015) - www.cngcoins.com.
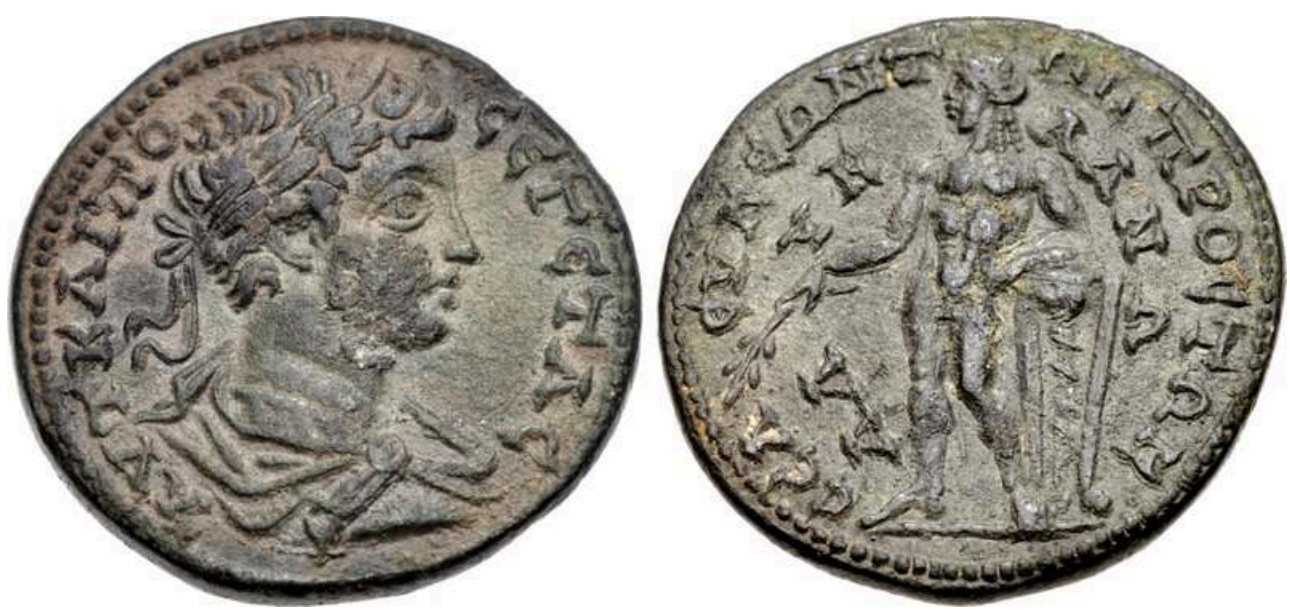

Fig. 5. Apollon Sarpédonios (revers). Séleucie, 209-211 ap. J.-C. (Geta).

CNG 91, lot 559 (19 septembre 2012) - www.cngcoins.com.
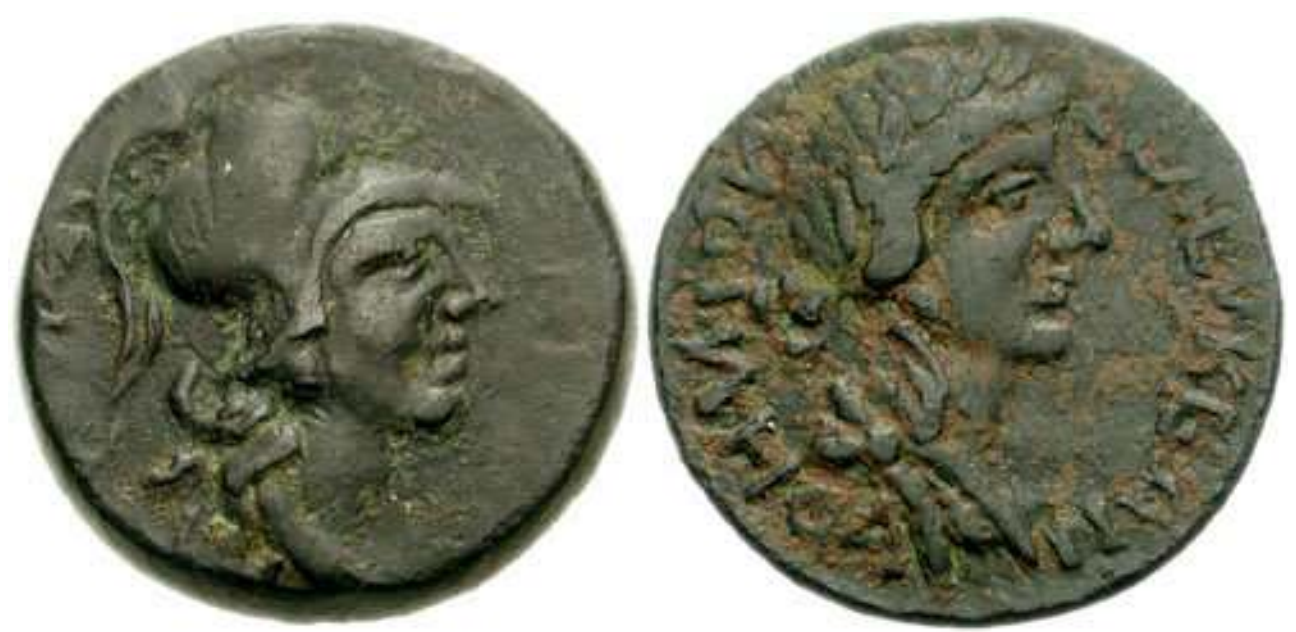

Fig. 6. Athéna et Apollon Sarpédonios (revers). Séleucie, " s. ap. J.-C.

CNG 134, lot 106 (1 ${ }^{\mathrm{er}}$ mars 2006) - www.cngcoins.com. 

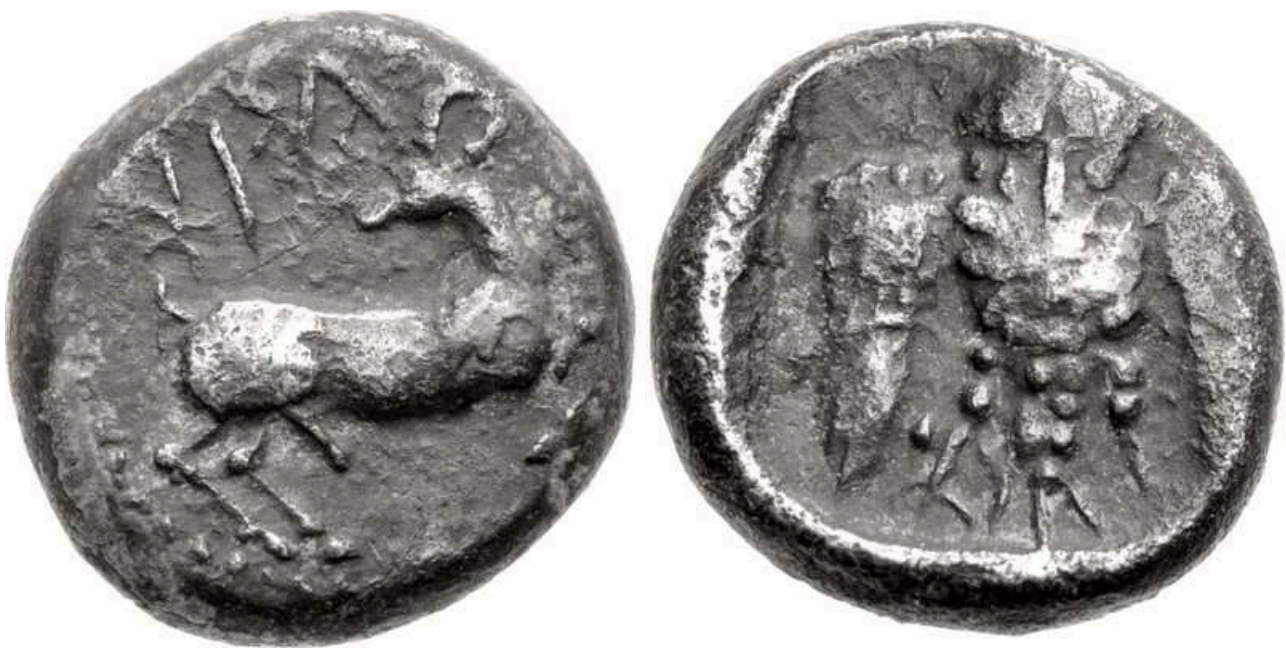

Fig. 7. Animaux attributs du dieu d'Ura (avers) et d'Athéna (revers). Ura, milieu du ve s. av. J.-C. CNG 96, lot 579 (14 mai 2014) - www.cngcoins.com.
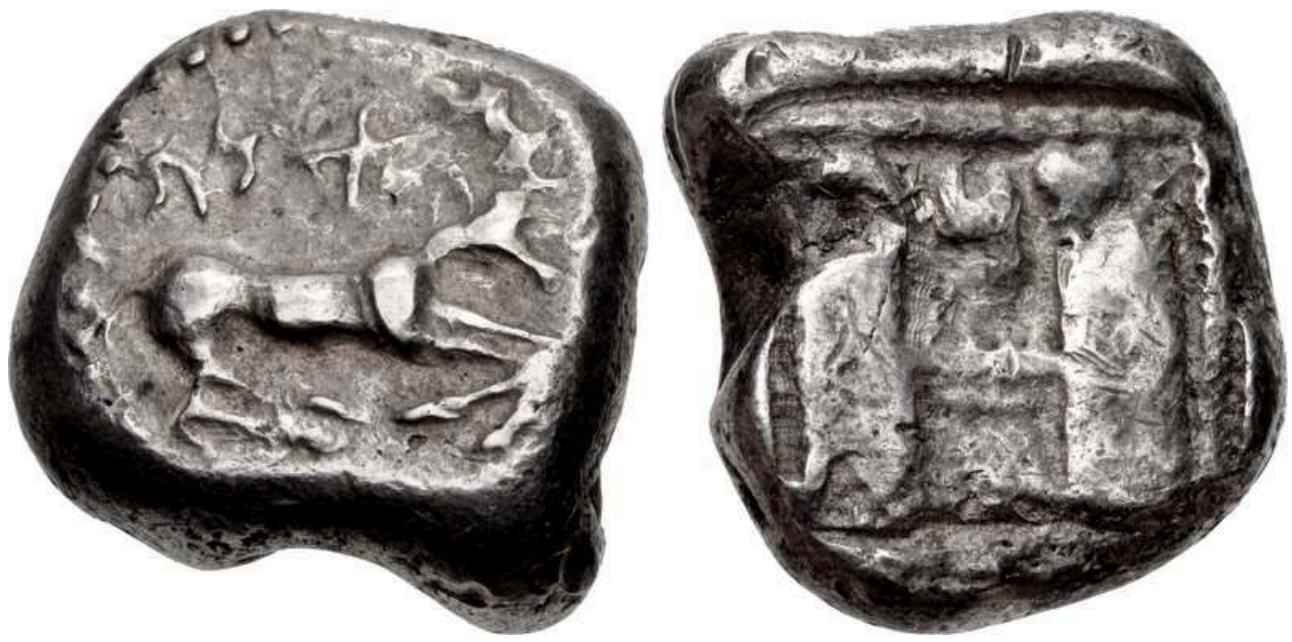

Fig. 8. Cerf, animal attribut du dieu d'Ura (avers). Ura, milieu du ve s. av. J.-C. CNG 102, lot 572 (18 mai 2016) - www.cngcoins.com.
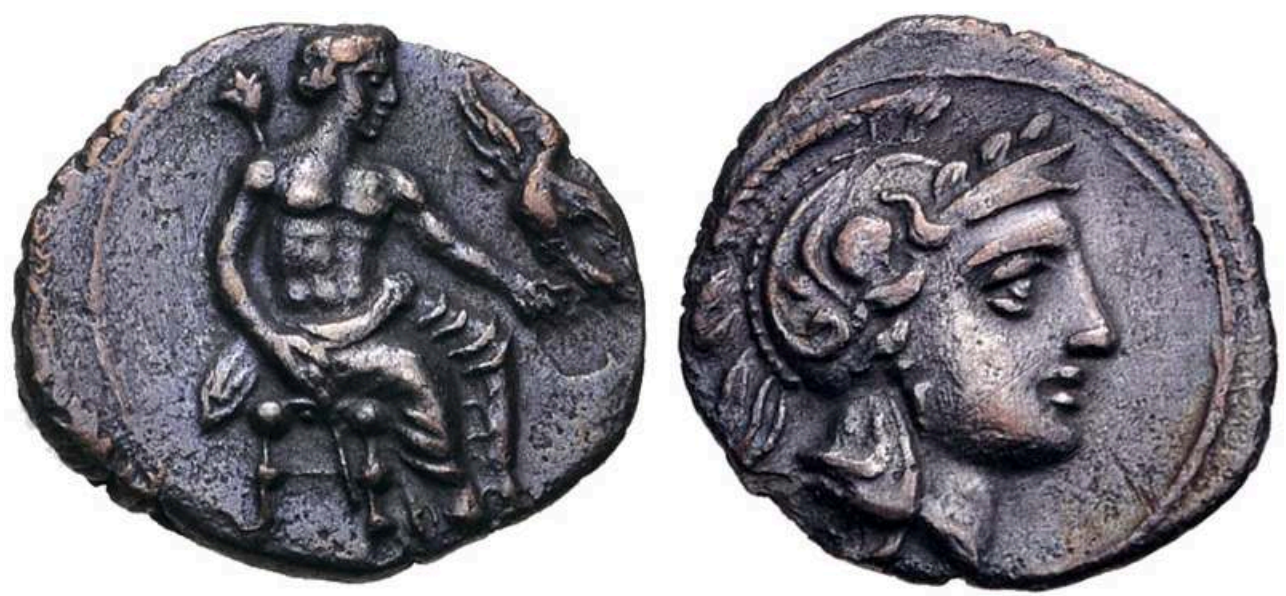

Fig. 9. Athéna (avers)/Dieu trônant tenant un oiseau (revers). Cilicie, Incertain, ıve s. av. J.-C. CNG 334, lot 149 (3 septembre 2014) - www.cngcoins.com. 

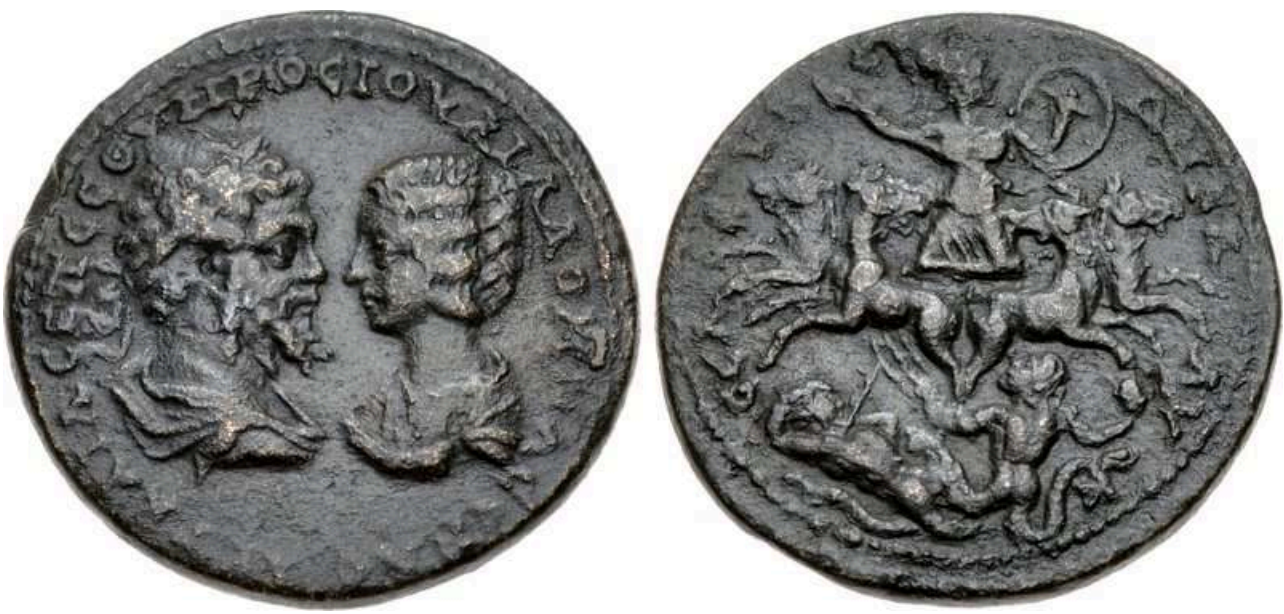

Fig. 10a. Athéna terrassant des géants anguipèdes (revers). Séleucie, 193-217 ap. J.-C. (Septime Sévère et Julia Domna).

CNG 88, lot 990 (14 septembre 2011) - www.cngcoins.com.
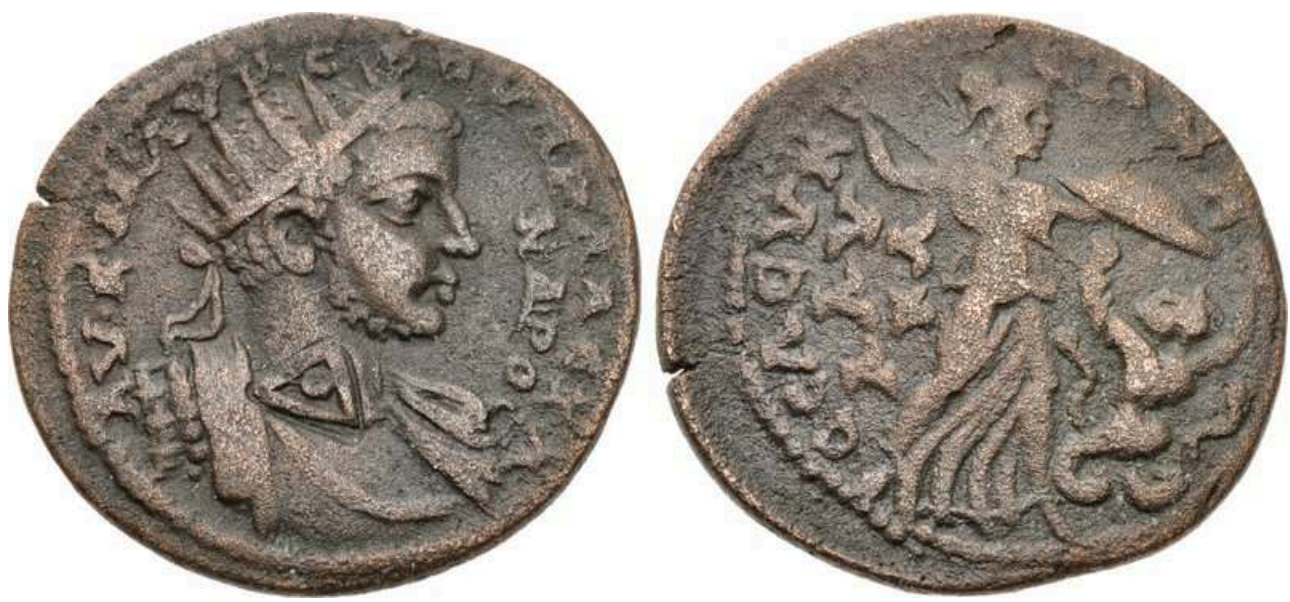

Fig. 10b. Sévère Alexandre portant une couronne radiée (avers)/Athéna terrassant un géant anguipède (revers). Séleucie, 222-235 ap. J.-C.

CNG 93, lot 886 (22 mai 2013) - www.cngcoins.com 


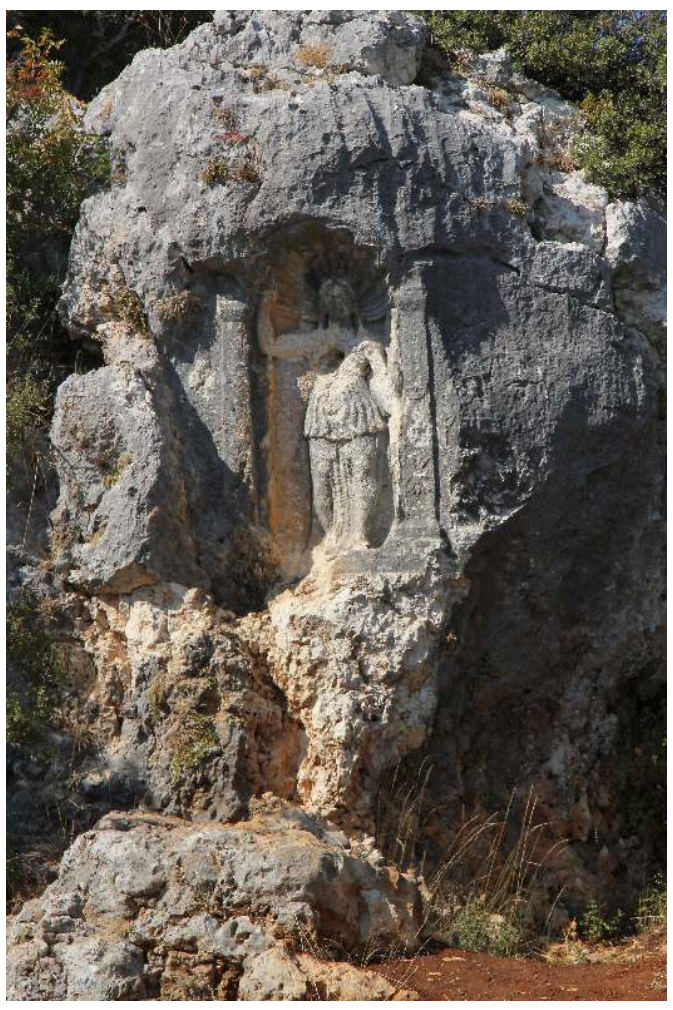

Fig. 11. Relief de Sömek représentant Athéna Oreia (Durugönül, Mörel [2012], p. 309).
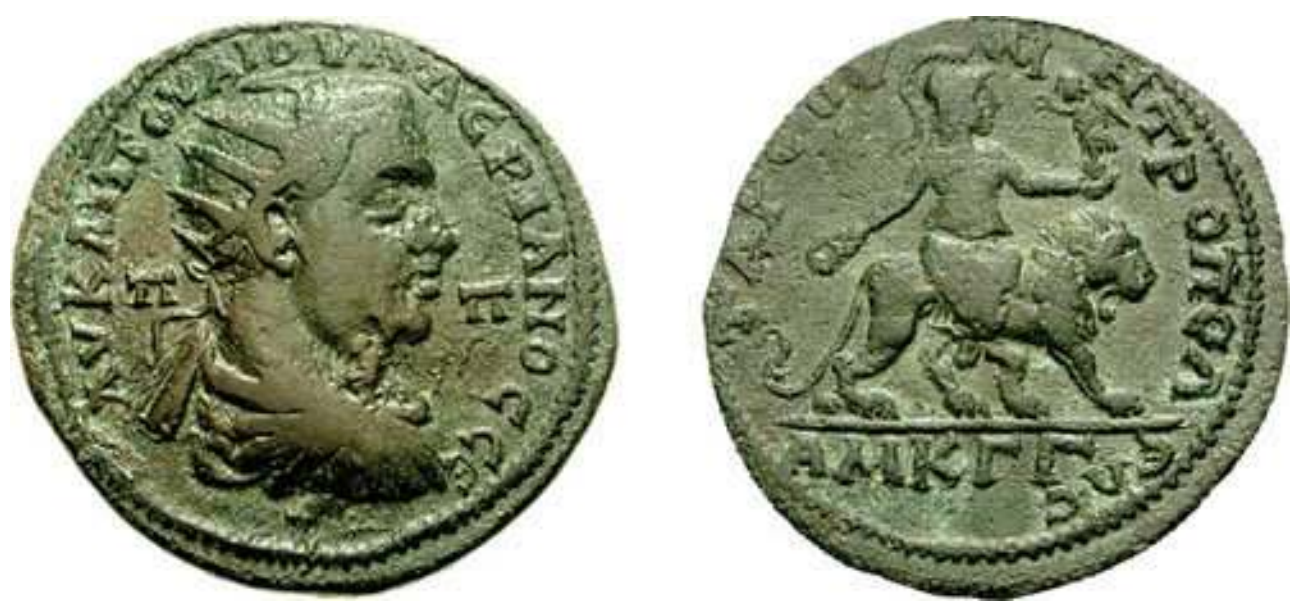

Fig. 12a. Athéna sur un lion (revers). Tarse, 253-260 ap. J.-C. (Valérien).

CNG 69, lot 1179 (8 juin 2005) - www.cngcoins.com. 

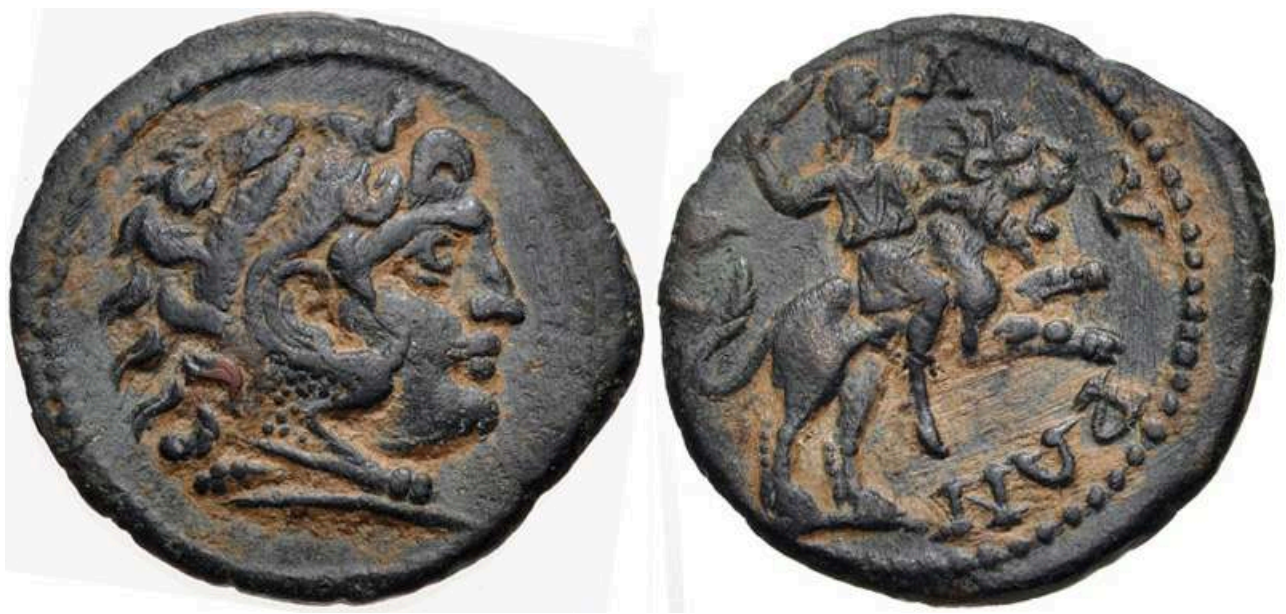

Fig. 12b. Divinité d'Isaura chevauchant un lion (revers). Isaura, fin ॥e s. - déb. ॥e ap. J.-C. CNG 321, lot 396 (24 septembre 2003) - www.cngcoins.com.
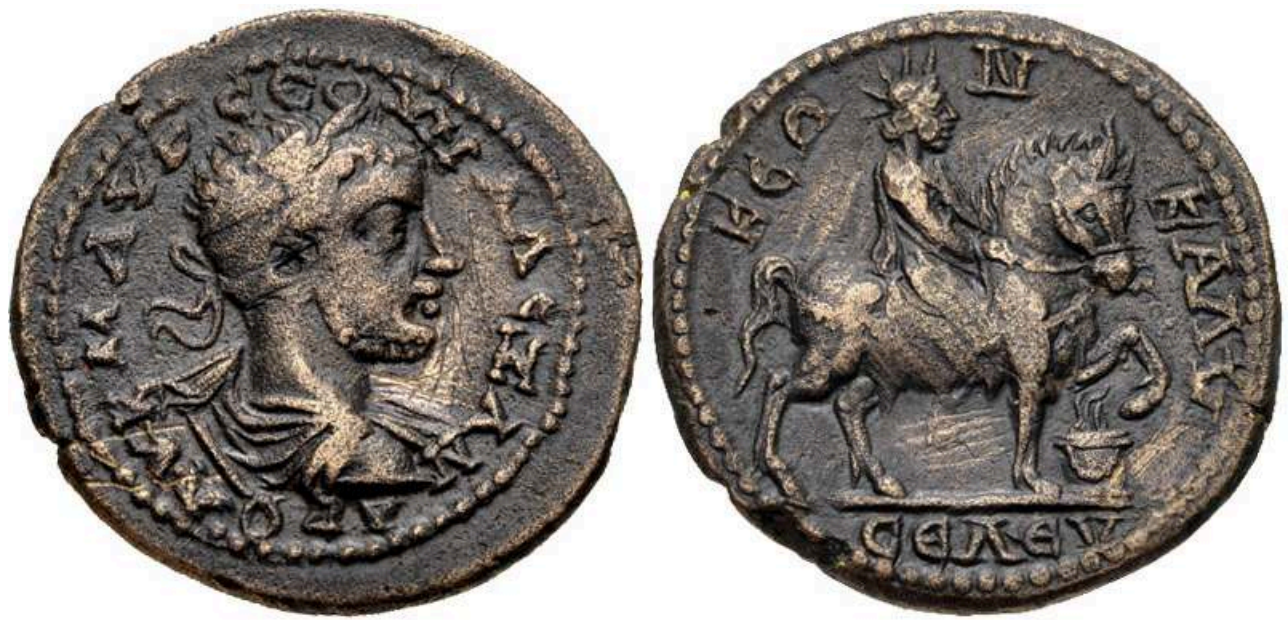

Fig. 13a. Apollon Sarpédonios à cheval (revers). Séleucie, 222-235 ap. J.-C. (Sévère Alexandre). CNG 304, lot 236 (12 juin 2013) - www.cngcoins.com.
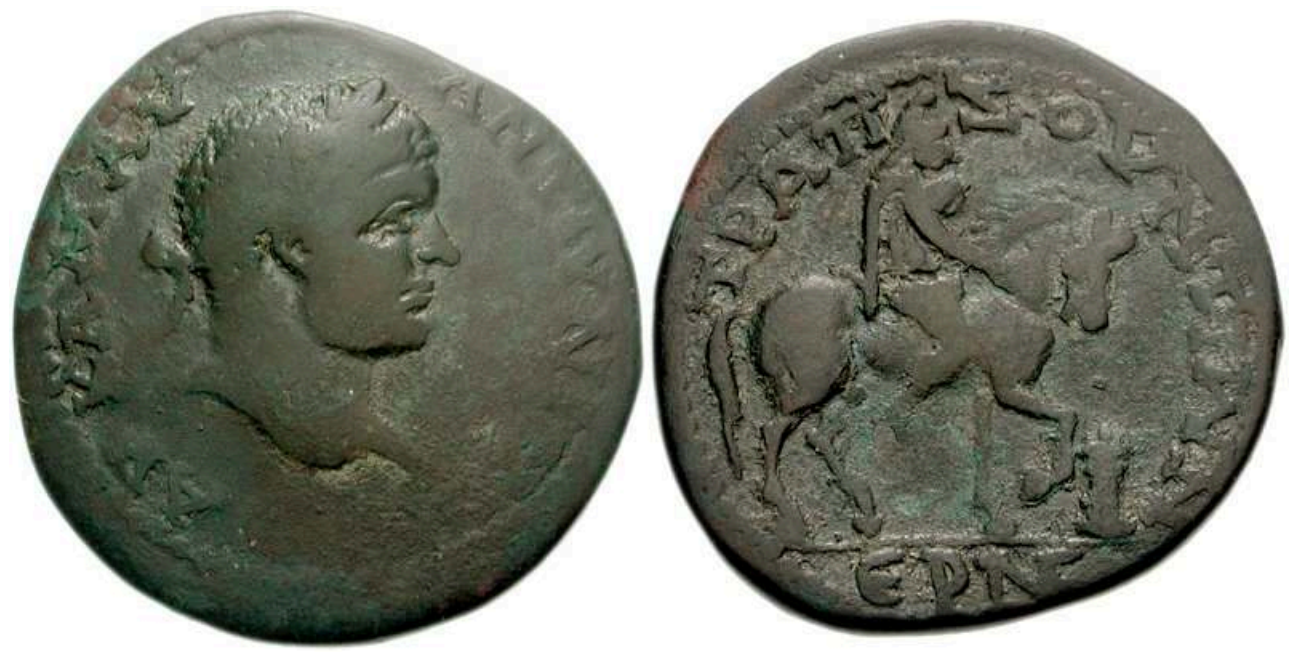

Fig. 13b. Mithra à cheval (revers). Trapezus (Pont), 198-217 ap. J.-C. (Caracalla).

CNG 160, lot 136 (14 mars 2007) - www.cngcoins.com. 

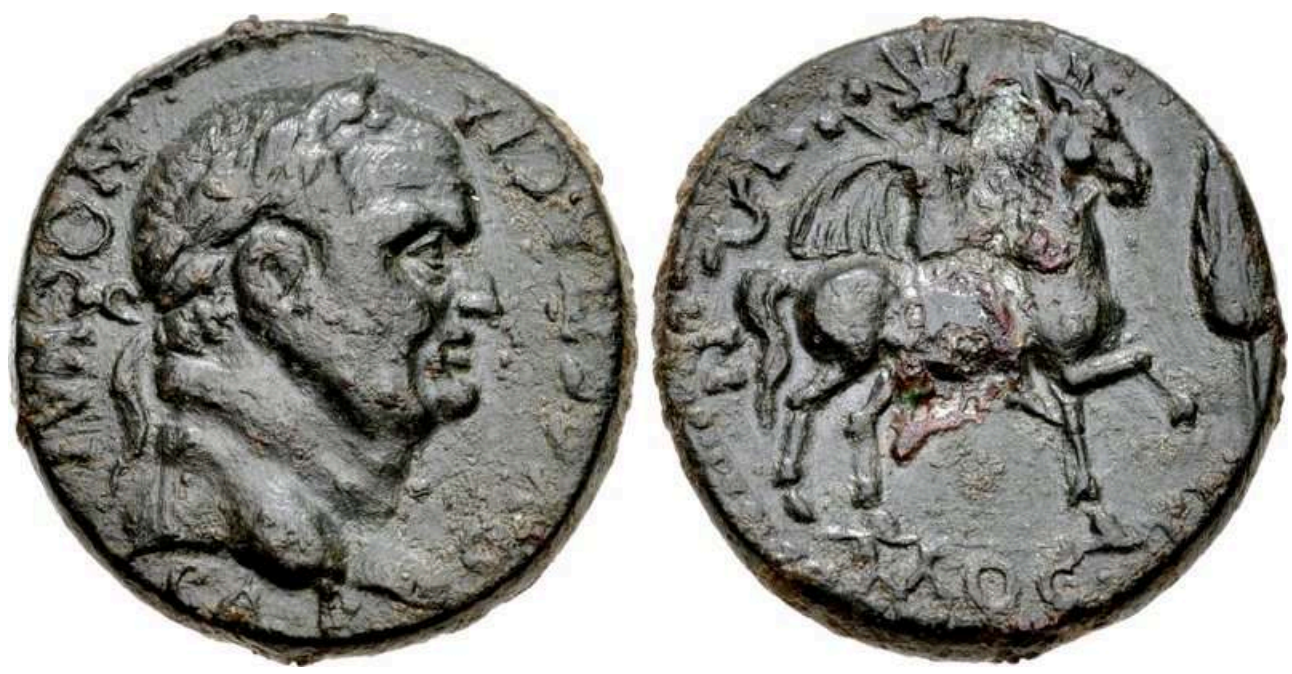

Fig. 13c. Le dieu de Mostène Sozon (revers). Mostène (Lydie), 69-79 (Vespasien). CNG 90, lot 994 (23 mai 2012) - www.cngcoins.com.
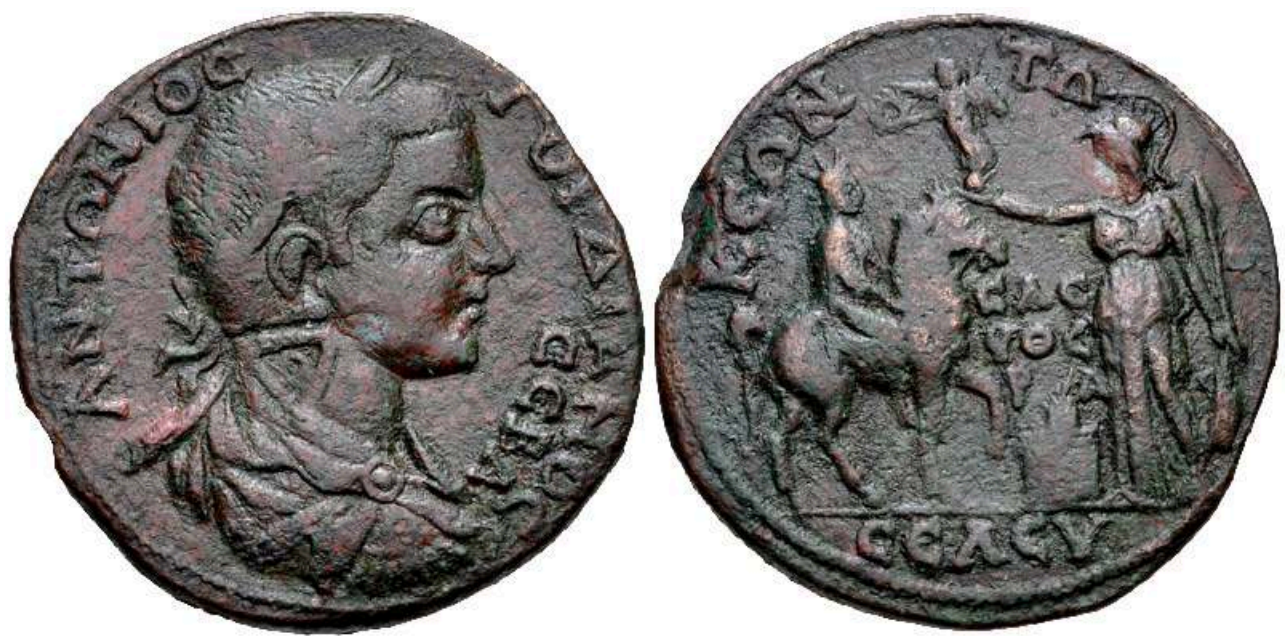

Fig. 13d. Apollon Sarpédonios à cheval et Athéna Niképhoros (revers). Séleucie, 238-244 ap. J.-C. (Gordien III).

CNG 872661 - www.cngcoins.com. 

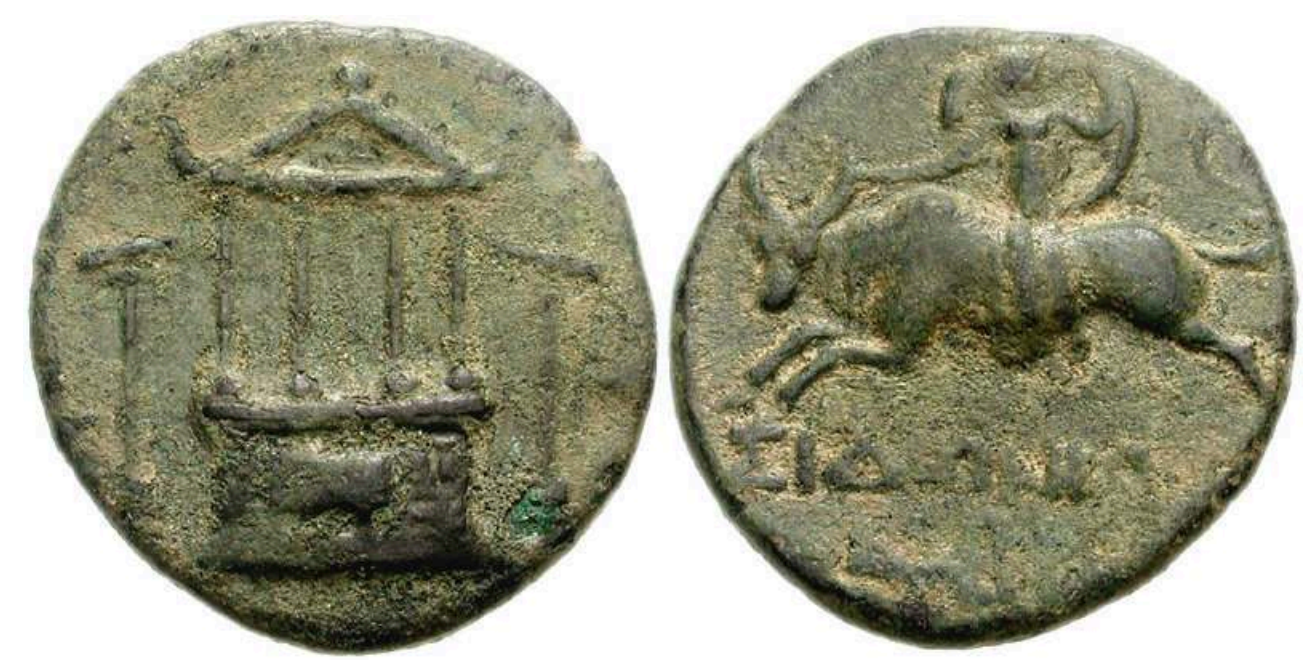

Fig. 14a. Europe chevauchant Zeus métamorphosé en taureau (revers). Sidon, 27 av. J.C.-14 ap. J.-C. (Auguste).

CNG 189, lot 120 (11 juin 2008) - www.cngcoins.com.
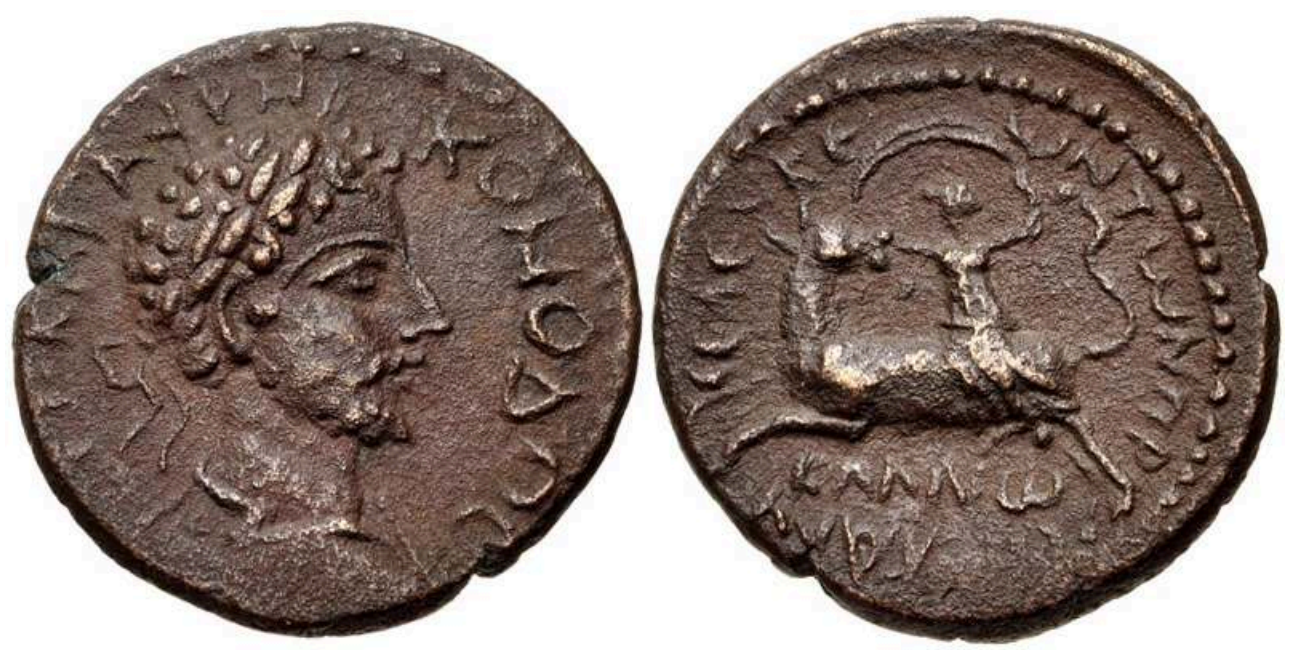

Fig. 14b. Europe chevauchant Zeus métamorphosé en taureau (revers). Séleucie, 177-192 ap. J.-C. (Commode).

CNG 328, lot 351 (11 juin 2014) - www.cngcoins.com.

\section{BIBLIOGRAPHIE}

J. ASSMANN, « Translating Gods: Religion as a Factor of Cultural (Un)Translatability », in S. BUdICK, W. ISER(éd.),The Translatability of Cultures. Figurations of the Space Between, Stanford, 1996, p. 25-36.

D. BAWANYPECK, «'Luwian' Religious Texts in the Archives of Hattusa », in A. Mouton, I. RUTHERFORD, I. YAKUBOVICH(éd.), Luwian Identities: Culture, Language and Religion Between Anatolia and the Aegean, Leiden/Boston, 2013, p. 159-177. 
D. BAWANYPECK, « Die Auguren und das hethitische Heer », in H. NEUMANN et al.(éd.),Krieg und Frieden im Alten Vorderasien, $52^{e}$ Rencontre Assyriologique Internationale, Münster, 17.-21. Jul. 2006, Münster, 2014 (Alter Orient und Altes Testament, 401), p. 97-107.

N. BELAYCHE et al. (éd.), Nommer les dieux. Théonymes, épithètes, épiclèses dans l'Antiquité, Turnhout, 2005.

-, « Introduction. Troisième partie : la construction du nom et les fonctions de l'épiclèse », in BELAYCHE et al. (2005), p. 211-212 [= BELAYCHE (2005a)].

-, « Introduction. Quatrième partie : les noms des dieux à l'épreuve de l'histoire », in BELAYCHE et al. (2005), p. 323-324 [= BELAYCHE (2005b)].

M. Bianco, C. Bonnet, « Sur les traces d'Athéna chez les Phéniciens »,Pallas [En ligne] 100 (mis en ligne le 15 avril 2016), consulté le 3 mars 2017. URL : http://pallas.revues.org/2887 ; DOI : 10.4000/pallas.2887, 2016.

J.D. BING, « Alexander's Sacrificedis praesidibus loci before the Battle of Issus », JHS 111 (1991), p. 161-165.

C. BONNET, A. DECLERCQ, I. SLOBODZIANEK (éd.), Les représentations des dieux des autres, Actes du Colloque FIGVRA Toulouse. 9-11 décembre 2010, Palerme, 2011 (Mythos, suppl. 2).

E. BORGIA, « Il culto di Athena Oreia in Cilicia », in M. MAZOYER(éd.),La campagne : espaces sauvages, terres domestiquées, Paris, 2003, p. 73-90.

A. BOUCHÉ-LECLERCQ, Histoire de la divination dans l'Antiquité III, Paris, 1880.

F. BRON, Recherches sur les inscriptions phéniciennes de Karatepe, Genève/Paris, 1979 (Hautes Études Orientales, 11).

P. BRULÉ, « Le langage des épiclèses dans le polythéisme hellénique », Kernos 11 (1998), p. 13-34.

O. CASABONNE, « Notes ciliciennes », AnAnt 7 (1999), p. 69-88.

-, La Cilicie à l'époque achéménide, Paris, 2004.

-, « Quelques Remarques et Hypothèses sur Ura et la Cilicie Trachée »,Colloquium Anatolicum IV, Istanbul, 2005, p. 67-81.

-, « Kataonia, Melitene, Kummanni, and the Problem of Komana »,Acta Orientalia Belgica XXII, Louvain-la-Neuve, 2009, p. 181-188.

-, A. PoRCHER, « Notes Ciliciennes », AnAnt 11 (2003), p. 131-140.

P. CHUVIN, « Apollon au trident et les dieux de Tarse », Journal des Savants (1981), p. 305-326.

G. COHEN, The Hellenistic Settlements in Europe, the Islands and Asia Minor, Berkley, Los Angeles, Oxford, 1995.

G. DAGRoN, Vie et Miracles de sainte Thècle. Texte grec, traduction et commentaire, Bruxelles, 1978 (Subsidia Hagiographica, 62).

-, D. FEISSEL, Inscriptions de Cilicie, Paris, 1987 (Travaux et mémoires du centre de recherche d'histoire et de civilisation de Byzance, Monographies, 4).

Ed. DHorme, R. Dussaud, Les Anciennes Religions Orientales. Tome 1, II : Les Religions de Babylonie et d'Assyrie. Les Religions des Hittites et des Hourrites, des Phéniciens et des Syriens, Paris, 1949. 
J. DALAISON, B. RÉMY,

« Les divinités d'origine indigène et iranienne sur le monnayage des cités du Pont sous les premiers Sévères ", RN 170 (2013), p. 29-60.

M. DUNAND, « Verroteries d'enfants dans le temple d'Echmoun à Sidon », Bulletin du Musée de Beyrouth 30 (1978), p. 47-50.

A. DUPONT-SOMMER, L. ROBERT, La déesse de Hiérapolis-Castabala, Paris, 1964.

S. DURUGÖNÜL, Die Felsreliefs im Rauhen Kilikien, Oxford, 1989.

-, A. MöREL, «Evidence of Judaism in Rough Cilicia and its Associations with Paganism »,MDAI(I) 62 (2012), p. 303-322.

D. FEISSEL, « Remarques de toponymie syrienne d'après des inscriptions grecques chrétiennes trouvées hors de Syrie », Syria 59, fasc. 3-4 (1982), p. 319-343.

A.J. Festugière, « Les énigmes de sainte Thècle », Comptes rendus des séances de l'Académie des Inscriptions et Belles-Lettres, $112^{\mathrm{e}}$ année, 1 (1968), p. 52-63.

S. FOURRIER, « Cyprus and Cilicia in the Iron Age: a Review of the Evidence », in Acts of the 3rd International Symposium on the Cilician Archeology, "Cilicia in the Classical Ages », June 2002, Mersin, Turkey, OLBA 7 (2003), p. 79-91.

K. FREU, M. MAZOYER, Les Hittites et leur histoire. Les Royaumes néo-hittites à l'Âge du Fer, Paris, 2012 (Kubaba, série Antiquité).

P. O. HARPER, H. PITTMAN, L'Égypte et le Proche-Orient par les conservateurs du Metropolitan Muséum of Art, Paris, 1987.

J. HASTINGs et al., A Dictionary of the Bible, III, 1 (1906).

E. HERZFELD, S. GUYER, Monumenta Asiae Minoris Antiqua, II (Meriamlik und Korykos, zwei christliche Ruinenstätten des Rauhen Kilikiens), Manchester, 1930.

M.C. Hoff, R.F. TownSEND(éd.),Rough Cilicia, New Historical and Archaeological Approaches, Oxford, 2013.

A. Houghton, «The Seleucid Mint of Mallos and the Cult Figure of Athena Magarsia ", in A. Hougthon, S. Hurter, P. ERHART MOtTAHEDEH, J. Ayer SCOTT(éd.),Festschrift für Leo Mildenberg, Wetteren, 1984, p. 91-110.

Ph. H.H. HOUWINK TEN CATE, The Luwian population groups of Lycia and Cilicia Aspera during the Hellenistic period, Leiden, 1961.

M. HUTTER, « Aspects of Luwian Religion », in H.C. MELChERT(éd.),The Luwians, Boston/Leiden, 2003, p. 211-280.

A.M. JASINK, L. BOMBARDIERI, « The Göksu River Valley from Late Bronze to Iron Age: local cultures, external influences, and relations with foreign peoples ", in M.C. HoFf, R.F. TownSEND(éd.), Rough Cilicia, New Historical and Archaeological Approaches, Oxford, 2013, p. 16-26.

E. KozAL, « Analysis of the Distribution Patterns of Red Lustrous Wheel-made Ware, Mycenaean and Cypriot Pottery in Anatolia in the 15th-13th Centuries B.C. », in B. FISCHER, H. GENZ, É. JEAN, K. KöROĞLU(éd.),Identifying Changes: The Transition from Bronze to Iron Ages in Anatolia and its Neighbouring Regions. Proceedings of the International Workshop Istanbul, November 8-9, 2002, Istanbul, 2003, p. 65-77. 
E. LAROCHE, « Recherches sur les noms des dieux hittites », RHA 7 (1946-1947), p. 7-139.

-, Recueil d'onomastique hittite, Paris, 1952.

-, Les noms des Hittites, Paris, 1966 (Études Linguistiques, 4).

R. LEBRUN, « L'Anatolie et le monde phénicien du $x^{\mathrm{e}}$ au IV siècle av. J.-C. », in Ed. LIPINSKI(éd.), Phoenicia and the East Mediterranean in the first millenium B.C. Proceedings of the Conference held in Leuven from the $14^{\text {th }}$ to the $16^{\text {th }}$ of November 1985, Leuven, 1987 (Studia Phoenicia, 5), p. 23-33.

—, «À propos des déesses Maliades et de quelques épiclèses gréco-asianiques », Kernos 2 (1989), p. 83-88.

M. Lejeune, « Le dossier sa-ra-pe-da du scribe 24 de Pylos », Minos 14 (1973), p. 60-76.

A. LEMAIRE, « Remarques à propos du monnayage cilicien d'époque perse et de ses légendes araméennes »,in R. DESCAT (éd.), L'or perse et l'histoire grecque, REA 91 (1989), no 1-2, p. 141-156.

Ed. LIPINSKI, Dieux et déesses de l'univers phénicien et punique, Leuven/Paris, 1995.

-, Resheph, A Syro-Canaanite Deity, Leuven/Paris/Walpole, 2009.

F. Lopez PARDo, A. MEderos Martin, La factoría fenicia de la isla de Mogador y los pueblos del Atlas, Santa Cruz de Tenerife, 2008.

G. MACMAHON, The Hittite state cult of the tutelary deities, Chicago, 1991 (Assyriological Studies, 25).

T.S. MACKAY, « The Majors Sanctuaries of Pamphylia and Cilicia », ANRW II 18, 3 (1990), p. 2110

2113.

J.-P. MARTIN, « Sol Invictus : des Sévères à la tétrarchie d'après les monnaies »,CCG 11 (2000), p. 297300.

O. MASSON, « Cultes indigènes, cultes grecs et cultes orientaux à Chypre », in

Éléments orientaux dans la religion grecque ancienne, colloque de Strasbourg, 22-24 mai 1958, Paris, 1960, p. 129-142

-, « Pèlerins chypriotes en Phénicie (Sarepta et Sidon) », Semitica 32 (1982), p. 45-49.

M. MÜNNICH, The God Resheph in the Ancient Near East, Tübingen, 2013 (Orientalische Religionen in der Antike, 11).

T.B. MITFORD, « The Cults of Roman Rough Cilicia », ANRW II 18, 3 (1990), p. 2131-2166.

Cl. MUtAFIAN, La Cilicie aux carrefours des empires, Paris, 1988.

H. Nicolet-PierRe, « Monnaies de bronze de Cilicie (Séleucie du Kalykadnos) », RN 13 (1971), p. 2637.

C. NISSEN, « Un oracle médical de Sarpédon à Séleucie du Kalykadnos », Kernos 14 (2001), p. 111131.

M. ÖZSAIT, G. LABARRE, N. ÖZSAIT,

« Les reliefs rupestres et les inscriptions de Keçili-Yaniktaş (Pisidie) »,AnAnt. 12 (2004), p. 61-82.

H.W. PARKE, The oracles of Apollo in Asia Minor, Londres/Sydney/Dover, 1985.

R. PARKER,« The Problem of the Greek Cult Epithet »,OAth 25 (2003), p. 173-183.

-, « Artémis Ilithye et autres : le problème du nom divin utilisé comme épiclèse ", in BELAYCHE et al. (2005), p. 219-226. 
Ch. PICARD, Éphèse et Claros. Recherches sur les sanctuaires et les cultes de l'Ionie du Nord, Paris, 1922.

S. PILHOFER, Romanisierung in Kilikien? : das Zeugnis der Inschriften, Munich, 2015.

J.B. PRITCHARD, Sarepta. A Preliminary Report on the Iron Age. Excavations of the University Museum of the University of Pennsylvania, 1970-72, Philadelphia, 1975.

-, « The Tanit Inscription from Sarepta », in H.G. NIEMEYER(éd.),Phönizier im Westen, Mainz, 1982, p. 85-92.

J.P. ReY-CoQUAIS, « Deir el-Qalaa », Topoi 9/2 (1999), p. 607-628.

E. PUECH, « Les inscriptions phéniciennes d'Amrit et les dieux guérisseurs du sanctuaire », Syria 63 (1986), p. 327-342.

E. RAIMOND, «L'oracle sarpédonien dans la Vie et les Miracles de sainte Thècle », in R. LEBRUN, A. DEGRÈve (éd.), Deus medicus. Actes du colloque organise à Louvain-la-Neuve les 15 et 16 Juin 2012 par le Centre d'histoire des Religions Cardinal Julien Ries, Turnhout, 2013, p. 284-297.

L. ROBERT, « Les conquêtes du dynaste lycien Arbinas », JS (1978), p. 3-48.

H. ŞAHIN, «A new dedication to Athena from Diocaesarea (Uzunburç) », Adalya 12 (2009), p. 221230.

M.S. SMITH, God in Translation. Deities in Cross-Cultural Discourse in the Biblical World, Grand Rapids, Cambridge, 2010.

N. THIERRY, « Le culte du cerf en Anatolie et la Vision de saint Eustathe », Monuments et mémoires de la Fondation Eugène Piot 72 (1991), p. 33-100.

A. TOURRAIX, Le mirage grec : l'Orient du mythe et de l'épopée, Besançon, 2000.

M.-C. TRemouille, « Kizzuwatna, terre de frontière », in E. JEAN, A. M. Dinçol, S. DurugöNüL(éd.),La Cilicie : espaces et pouvoirs locaux (II millénaire av. J.-C. - IV siècle ap. J.-C.). Actes de la Table Ronde d'Istanbul, 2-5 novembre 1999, Istanbul, 1999 (Varia Anatolica, 13), p. 57-78.

G. VARINLIOĞLU, « Une inscription de Mercure aux Portes de Cilicie », EA 11 (1988), p. 59-64.

F. VIAN, « Le mythe de Typhée et le problème de ses origines orientales », in

Éléments orientaux dans la religion grecque ancienne, colloque de Strasbourg, 22-24 mai 1958, Paris, 1960, p. 17-37.

J. WALLENSTEN, « Dedications to Double Deities », Kernos [En ligne] 27 (2014), mis en ligne le $1^{\mathrm{er}}$ octobre 2016, consulté le 10 janvier 2017. URL : http://kernos.revues.org/2278 ; DOI : 10.4000/ kernos.2278.

P. WATHELET, Dictionnaire des Troyens de l'Iliade II, Liège, 1988 (Documenta et Instrumenta, 1).

I.J. WINTER, « On the Problems of Karatepe, the Relief in their context », AnSt 29 (1979), p. 115-151.

F. WOUdHuIZEN, « On the Reading of the Luwian Hieroglyphic Legends of the Schimmel Rhyton », Colloqium Anatolicum XII (2013), p. 333-344.

P. XELLA, « La religion phénico-punique au Maroc. Les apports de l'épigraphie », in Lixus. Actes du colloque de Larache (8-11 novembre 1989), Rome, 1992 (Collection de l'École française de Rome, 166), p. 137-143. 


\section{NOTES}

1. Sur l'histoire de la Cilicie Trachée et notamment de la vallée du Göksu pour l'ensemble de la période traitée ici, nous renvoyons à l'ouvrage dirigé par HOFF, TOWNSEND (2013). Sur la région du Kalykadnos pour la période $\mathrm{du}$ XIII ${ }^{\mathrm{e}}$ au VI ${ }^{\mathrm{e}}$ siècles avant J.-C., voir en particulier la très bonne miseau-point de JASINK, BOMBARDIERI (2013). Pour le royaume de Pirindu et la période achéménide, voir CASABONNE (2004), p. 142-165. Pour les périodes hellénistique et romaine, voir par exemple : COHEN (1995), p. 369 sq. et PILHOFER (2015).

2. CASABONNE (2004), p. 143 avec références.

3. L'identification d'Ura avec Séleucie semble la plus probable mais elle fait encore débat. Voir infra.

4. Casabonne (2004), p. 84-85 et 151.

5. Probablement l'actuelle station balnéaire et portuaire de Taşucu à quelques kilomètres au sud de Silifke-Séleucie : cf. CASABONNE (1999), p. 73.

6. Ibid. p. 145.

7. Ammien Marcellin, XIV, 8, 2 ; Stéphane de Byzance, s.v. « Séleucie».

8. Strabon, XIV, $5,4$.

9. Diodore de Sicile, XXXII, 10, 2 ; Zosime, I, 57, 2.

10. Les sources chrétiennes le désignent quant à elles sous le nom de "Sarpédon » ou «Sarpédonios »: Vie de sainte Thècle, 27 ; Miracles de sainte Thècle, 1, 1; 11, 12;18, $30 ; 40,15,30$. Cf. DAGRON (1978) et NISSEN (2001), p. 119.

11. Strabon, XIV, $5,19$.

12. Pour une synthèse des différentes légendes se rapportant au héros Sarpédon, voir MUTAFIAN (1988), p. 79-83.

13. Homère, Iliade XVI, 671-675. Sur Sarpédon dans l'Iliade : Homère, Iliade VI, 198 sq. ; II, 876 ; V, 628 sq. ; XII, 101 sq., 290 sq. ; XVI, 419 sq., 666 sq. Voir également W ATHeLET (1988), p. 973 sq. La scène de l'enlèvement $d u$ corps de Sarpédon est représentée sur le célèbre «cratère de Cerveteri » ou « cratère d'Euphronios ».

14. Corpus hésiodique, fr. 140 Merkelbach-West ; Eschyle, Les Cariens ou Europe, fr. 99 Nauck-Snell ; Hérodote, I, 173 ; Strabon, XII, 8, 5 ; XIV, 1, 6 ; XIV, 3, 10 ; Apollodore, III, 1, 1-2.

15. Diodore de Sicile, V, 79, 3.

16. Apollodore, III, $1,2$.

17. WATHELET (1988), p. 302.

18. CASABONNE (1999), p. 73 avec référence à BRON (1976), p. 169.

19. CASABONNE, ibid.

20. RAIMOND (2013), p. 289. Voir aussi note no 15.

21. LAROCHE (1952), p. 35, no 628 ; LAROCHE (1966), p. 159, no 1128.

22. LAROCHE (1946-47), p. 76, s.v. Sarpa.

23. CASABONNE, ibid.

24. TourRAIX (2000), p. 44 avec références à LEJEUNE (1973).

25. Strabon, XIV, $5,4$.

26. Pline l'Ancien, $\mathrm{V}, 22$.

27. CASABONNE, ibid.

28. Eschyle, Les Suppliantes, 866-870.

29. Pomponius Mela, I, 13.

30. Skylax, 102.

31. Sur la datation du Périple, voir CASABONNE, ibid. p. 73 et note 6 avec références.

32. CASABONNE, ibid.

33. Sur cette hypothèse, voir CASABONNE, ibid. p. 74 avec références. 
34. Diodore de Sicile, XXXII, 10, 2.

35. Zosime, I, 57, 2-4.

36. Tertullien, De l'Âme, 46, 11.

37. BOUCHÉ-LECLERCQ (1880), p. 352-353.

38. Strabon, XIII, 1,$7 ; 1,49$ sq. et Pline l'Ancien, V, 32.

39. Strabon, XIV , 5,19 . Nous ne traiterons pas ici en détail le cas d'Artémis Sarpédonia qui pose quelques difficultés essentiellement dues à la faiblesse de la documentation. BOUCHÉ-LECLERCQ, ibid. p. 258 considère le culte oraculaire d'Artémis Sarpédonia comme une erreur de Strabon qui l'aurait confondue avec son frère. PICARD (1922), p. 397-398 et PARKE (1985), p. 194-196 voient quant à eux dans le passage du géographe, le témoignage d'un culte oraculaire associant les deux jumeaux à Séleucie. Dans le même sens, NISSEN (2001), p. 112 et 116-117, interprète les types monétaires des $\mathrm{I}^{\mathrm{er}}$ et $\mathrm{II}^{\mathrm{e}}$ siècles ap. J.-C. figurant les bustes affrontés d'Apollon et d'une divinité féminine, comme l'indice d'un culte oraculaire d'Artémis Sarpédonia à Séleucie. Cette divinité est toutefois le plus souvent représentée sur les monnaies avec un calathos et une cornucopia et nous y verrions plutôt la déesse Tyché qui figure très fréquemment sur les monnaies de Séleucie dès l'époque hellénistique. Ainsi, l'association des deux bustes voudrait peut-être signifier que la fortune de la cité est liée au culte d'Apollon Sarpédonios. Car le principal problème de ces interprétations vient du fait qu'elles reposent sur une lecture quelque peu forcée du passage de Strabon. Il convient en effet de souligner que le géographe n'évoque Artémis Sarpédonia qu'à la toute fin de sa description géographique de la Cilicie (paragraphe 19) selon une logique ouest-est, avant de passer à « la première ville syrienne ». Bien que sa connaissance de la Cilicie ait parfois été mise en doute, il aurait été plus logique pour le géographe d'aborder le cas d'Artémis Sarpédonia au paragraphe 4, relativement développé, qu'il consacre à Séleucie et dans lequel il évoque également le cap Sarpédon. Situer un culte oraculaire d'Artémis Sarpédonia à l'est de la Cilicie semblerait donc plus prudent malgré l'absence d'autre référence sur la déesse, lacune qui n'est finalement pas vraiment surprenante si l'on songe par exemple à l'immense proportion de types monétaires représentant le portrait d'une divinité dont on ne connaît rien par ailleurs, surtout pour ces régions orientales peu connues et tardivement hellénisées.

40. Zosime, I, 57, 2-4.

41. CASABOnNe (2003), p. 135.

42. Pline l'Ancien, $\mathrm{X}, 75$.

43. Cicéron, De la Divination I, 2. Voir aussi I, 92 et I, 94.

44. HUTTER (2003), p. 229.

45. BAWANYPECK (2013), cf. notamment c.g. VboT 24 iii 4ff ; KBo 12.96 ; KBo 17.105+ ; KBo 20.107+.

46. HUTTER (2003), p. 236.

47. MAC-MAHON (1991).

48. BAWANYPECK (2013), p. 164. 'LAMMA kuškuršaš, et son groupe des Sept, rappelle le dieu akkadien de la peste, Irra à la tête des sept démons maléfiques. Cf. DHORME (1949), p. 264-265.

49. HUTTER, ibid.

50. BAWANYPECK (2014), p. 99.

51. FREU, MAZOYER (2012), p. 237. Le nom du dieu-au-cerf au I ${ }^{\mathrm{er}}$ millénaire est transcrit en Runtiyas ou en Runta.

52. Voir notamment HUTTER (2003), p. 229.

53. Metropolitan Musem of Art, Inv. 1989.281.10

54. THIERRY (1991), p. 68-70.

55. CASABONNE (2003), p. 135, avec référence à HouwinK TEN CATE (1961), p. 212-214.

56. Voir notamment NICOLET-PIERRE (1971).

57. Sur la lecture de la légende araméenne 'RH et de sa mise en relation avec la cité d'Ura:

cf. LEMAIRE (1989), p. 150-154. 
58. Sur l'animal cornu attribut d'Apollon Sarpédonios, via son interpretatio phénicienne Resheph : voir infra.

59. Sur l'identification d'Ura à Séleucie, voir notamment CASABONNE (2005) et JASINK, BOMBARDIERI (2013) et supra.

60. Contrairement à ce qu'affirme C ASABONNE (1999), p. 72, Athéna n'est cependant jamais qualifiée de «Sarpédonia » dans les sources païennes ou chrétiennes.

61. DAGRON (1978), p. 84-94.

62. L'auteur est originaire d'Isaurie qui correspond environ à cette époque à la Cilicie Trachée et que Dioclétien a renommée ainsi au moment où il a séparé la Trachée du reste de la province de Cilicie. Séleucie-du-Kalykadnos est nommée par les auteurs tardifs Séleucie-d'Isaurie. La province d'Isaurie de l'Antiquité tardive recouvre ainsi une aire géographique différente de la région d'Isaurie (capitale Isaura, moderne Bozkır), antérieurement comprise comme la voisine septentrionale de la Cilicie Trachée, en plein Taurus. La frontière entre ces deux régions culturellement très proches et historiquement très liées reste difficile à tracer. Voir notamment CASABONNE (2004), p. 28-29.

63. DAGRON (1978), p. 84.

64. Ibid., p. 83.

65. RAIMOND (2013), p. 286 notamment.

66. DAgron (1978), p. 219-221. Vie de sainte Thècle, 12

67. La Vie de sainte Thècle, 20, évoque cependant un bassin de phoques et non de serpents. Cf. DAGRON (1978), p. 251 et RAIMOND, ibid.

68. NISSEN (2001), p. 127 ; HERZFELD, GUYER (1930).

69. MITFORD (1990), p. 2148 ; BORGIA (2003).

70. MITFORD, ibid.

71. Sur Athéna Oreia, voir également ŞAHIN (2009).

72. Voir notamment DURUGÖNÜL (1989), p. 50-51.

73. Sur Kiršu, voir notamment CASABONNE, ibid. p. 151-165. Pour les étymologies de Kiršu et Krisoa, voir BORGIA, ibid. p. 75.

74. CASABONNE (2004), p. 143.

75. Miracles de sainte Thècle, 5 ; DAGRON, ibid. p. 299. Sainte Thècle s'illustre aussi lors des sièges d'Iconium (Mir. 6), de Dalisandos (Mir. 26) et de Sélinonte (Mir. 27).

76. DURUGÖNÜL, ibid.

77. Voir notamment HougHTON (1984).

78. Miracles de sainte Thècle, 11 ; DAGRON, ibid. p. 315.

79. Miracles de sainte Thècle, 26 ; DAGRON, ibid. p. 357.

80. Strabon, XII, 2,7 ; DUPONT-SOMMER, ROBERT (1964).

81. DAGRoN (1978), p. 85.

82. LEBRUN (1980), p. 49. Nous renvoyons notamment à l'Ishtar guerrière d'Arbèles telle qu'elle est représentée sur la stèle du viII ${ }^{\mathrm{e}}$ siècle conservée au musée du Louvre (inv. AO 11503). Elle y figure sous son aspect viril dressée sur un lion et portant les armes tandis qu'un disque radié surmonte sa tiare à corne.

83. L'identification généralement admise de Kummanni/Comana de Cataonie pose en effet quelques problèmes et son identification avec Hiérapolis-Castabala nous semble plus convaincante. Cf. CASABONNE (2009), p. 182-183 et TRÉMOUILLE (2001).

84. LEBRUN (1989), p. 87-88.

85. Contra NISSEN (2001) qui ne voit en sainte Thècle que la continuité du seul Sarpédon puisque la sainte récupère ses pouvoirs thérapeutiques. 
86. BING (1991), p. 163-164, voit également dans l'Athéna représentée sur les monnaies d'Issos du $\mathrm{IV}^{\mathrm{e}}$ siècle av. J-C. une représentation grecque de la déesse IšHara/Ištar.

87. CASABONNE (1999), p. 80.

88. DAGRON (1978), p. 84 ; Vie de sainte Thècle, 557 B.

89. DAGRON, ibid. p. 100.

90. Miracles de sainte Thècle, 23 ; DAGRON, ibid. p. 363.

91. KBo 15.36+ iii 7'-8', KUB 41.0 rev. 8'-9'. Cf. MAC-MAHON (1991), p. 45.

92. KUB 27.1 i 66 ; MAC-MAHON (1991), p. 40.

93. WOUDHUIZEN (2013), p. 337.

94. Quinte Curce, III, 7.

95. KAI 26=TSSI III, 15, A, II,10-11.

96. BRON (1979), p. 185.

97. CASABONNE (2003), p. 134-135.

98. LIPINSKI (1995), p. 187.

99. LEMAIRE (1989), p. 153.

100. Ibid., p. 150-154 et pl. III.

101. Ibid., p. 150.

102. L'évocation du dieu Resheph par le bouc se comprendrait du reste aisément en Cilicie, connue dans l'Antiquité pour ses grands troupeaux de chèvres à tel point qu'une étoffe grossière en poils de chèvre portait le nom de cilicium. Saint Paul, originaire de Tarse, exerçait le métier de fabricant de tentes confectionnées à partir du cilicium (cf. Paul, 18, 3). Le bouquetin devait par ailleurs être très familier aux populations d'Ura/Séleucie entourée des hautes montagnes du Taurus où l'animal est dans son élément.

103. Le très riche répertoire iconographique des monnaies tarsiotes fait l'objet de nombreuses discussions. Voir notamment CHUVIN (1981) ; CASABONNE (2004), p. 123-131 avec références.

104. Sur la question de la traduction et de la représentation de dieux étrangers, voir notamment AsSMANN (1996) ; SMITH (2010) ; WALLENSTEN (2014) ; BONNET, DECLERCQ, SLOBODZIANEK (2011).

105. VIAN (1960), p. 28. Pour le mythe à Korykos: Oppien, III, 21-25. Strabon, XIV, 6 décrit le phénomène hydrologique à Korykos : "On y remarque aussi une grotte contenant une large source, d'où s'échappe une eau pure et transparente, assez abondante pour former un fleuve, qui dès sa naissance se perd sous terre, coule ainsi invisible un certain temps, et ne reparaît que pour déboucher dans la mer sous le nom de Picron hydôr (l'eau amère). »

106. D AGRon, Feissel (1987), no 18. Les influences orientales dans la région de Korykos sont attestées à des époques diverses.

107. LIPINSKI (1995), p. 180 avec réf.

108. Dans quatre textes ougaritiques (RS $19.013: 2$; RS $24.250^{+}: 1$; RS $24.294: 9$; RIH 77/10B $: 1-$ 2) est mentionnée la locution «ršp higb». Différentes traductions de higb ont été proposées donnant principalement à la locution le sens de " gardien de l'entrée, portier » ou « sauterelle » (Cf. MüNNICH [2013], p. 151). D’après M. Münnich, on justifie la traduction par « sauterelle » dans la mesure où Resheph est aussi un dieu destructeur au même titre que ces insectes qui ravagent parfois les récoltes et entraînent la famine. L'auteur remarque cependant que le dieu Resheph n'est jamais associé à des criquets ou des sauterelles ni dans l'iconographie, ni dans les sources littéraires. Mais si l'on admet l'association de Resheph avec Apollon Sarpédonios dans la région d'Ura/Séleucie, on trouverait dans le passage de Zosime (I, 57, 2-4. ; voir supra), bien que tardif, un lien indirect de Resheph avec les sauterelles contre lesquelles Apollon Sarpédonios, protecteur des récoltes, remettait à ceux qui pâtissaient de leur fléau, des oiseaux pour les chasser. Comme maître de la nature et des animaux sauvages, le dieu Sarpédonios contrôle aussi bien les oiseaux que les sauterelles. Il est donc responsable des destructions provoquées par ces insectes qu'il peut déchaîner si l'on oublie de lui rendre grâce. À l'inverse, il a le pouvoir 
d'envoyer leur principal prédateur pour les chasser, devenant à ce titre un dieu tutélaire, protecteur des récoltes. Si l'on accepte cette traduction, nous aurions ici un autre aspect qui aurait pu faciliter un rapprochement entre Apollon et Resheph dans la région d'Ura/Séleucie.

109. LIPINSKI (1995), p. 187.

110. MASSON (1960), p. 135.

111. BIANCO, BONNET (2016), § 27. Le cas d'Idalion présente ainsi de nombreux points communs avec celui de Séleucie-du-Kalykadnos.

112. KOZAL (2003) ; CASABONNE (2005), p. 73 ; JASINK, BOMBARDIERI (2013).

113. Tacite, Histoires II, 3. Différents mythographes évoquent des échanges culturels entre Chypre et la Cilicie : Apollodore, III, 14, 3 ; Démodocos, Anthologie Palatine XI, 236.

114. Strabon, XVI, 6, 3.

115. Claude Elien, De la Nature des Animaux XI, 7.

116. FOURRIER (2003), p. 83, évoque notamment les liens d'Apollon avec le cerf à Chypre.

117. CASABONNE (2004), p. 79.

118. VARINLIOĞLU (1988).

119. HASTings et al. (1906), s.v. Locust.

120. Pausanias, $\mathrm{I}, 24,8$.

121. DALAison, RÉMY (2013),p. 40.

122. Voir notamment ÖZSAIT, LABARRE, ÖZSAIT (2004).

123. MARTIN (2000).

124. MAC-MAHON (1991).

125. Skylax, 102. Sur la datation du passage : cf. note 31 .

126. PARKER (2005), p. 219. Voir également BRULÉ (1998).

127. BeLAYCHE (2005a), p. 211. Sur ces questions voir aussi PARKER (2003) et plus généralement BELAYCHE et al. (2005).

128. PARKER (2005), p. 224.

129. DAGRON (1978), p. 86-87.

130. Miracles de sainte Thècle, 40, 29-31 : traduction de DAGRON (1978). Cf. NISSEN (2001), p. 121.

131. RAIMOND (2013), p. 290 avec réf. ; ROBERT (1978), p. 35

132. Il est vrai que les quelques sources à disposition sur le culte de Sarpédon en Lycie ne permettent pas de connaître la nature du culte dont il faisait l'objet et rien n'indique non plus qu'il ne disposait pas de tels pouvoirs en Lycie. Sa renommée ne devait toutefois pas dépasser le cadre de la stricte Lycie.

133. PARKER (2005). À propos de ce type de théonyme double, R. Parker remarque que « dans tous les cas, il y a une différence de genre entre les deux divinités qui sont ainsi associées: si le substantif est un dieu, c'est bien une déesse qui figure dans la forme adjectivale, et inversement ». Il cite toutefois une exception, « Zeus Areios », qui ne serait qu'un développement tardif de Zeus Arès : cf. PARKER (2005), p. 220.

134. BeLAyCHe (2005b), p. 323.

135. Les deux formes y sont employées indistinctement pour désigner le $\delta \alpha i ́ \mu \omega v$ de Séleucie.

136. WATHELET (1988), p. 975-976.

137. P.Oxy. 2617, 6.

138. Palaiphatos, 31 .

139. Lopez PARDo, Mederos MARTIN (2008), p. 381-382.

140. Xella (1992), p. 141.

141. Ibid., p. 142

142. Ibid., p. 143 ; PRITCHARD (1982), p. 85-92.

143. Xella, ibid. 
144. PRITCHARD (1975).

145. TM.75.G.1557, recto, col. V. Cf. LIPINSKI (1995), p. 193.

146. Nous souhaitons remercier ici les évaluateurs de la revue Kernos pour nous avoir suggéré ce parallèle phonétique et sémantique avec «Carthage » pour approfondir notre hypothèse d'une proximité entre « Sarpédon » et « Sarepta ».

147. Voir supra.

148. Miracles de sainte Thècle, 1, 1-10, trad. de DAGRoN (1978).

149. Hésiode, fr. 140 Merkelbach-West; Eschyle, Les Cariens ou Europe, fr. 99 Nauck/Snell; Hérodote, I, 173 ; Strabon, XII, 8, 5 ; XIV , 1, 6 ; XIV, 3, 10 ; Apollodore, III, 1, 1-2. Cf. supra.

150. Apollodore, III, 1, 1-2. Cilix est, chez Apollodore, l'un des trois frères d'Europe partis à la recherche de leur sœur après son enlèvement par Zeus. Il est le fils d'Agénor, roi de Phénicie. Ce dernier ayant interdit à ses fils de rentrer en Phénicie sans leur sœur, les trois frères qui n'ont pu la retrouver s'établirent à l'étranger. Cilix s'installa dans la région qui prit son nom, la Cilicie.

151. Lucien, De la Déesse syrienne, $4:$ : On voit aussi, en Phénicie, un grand temple que possèdent les Sidoniens, consacré, disent-ils, à Astarté. Astarté, selon moi, c'est la lune. Mais, si l'on s'en rapporte à ce que m'a dit un des prêtres de ce temple, il est dédié à Europe » (trad. Eugène Talbot).

152. Lycophron, Alexandra, 1300.

153. III Rois, XVII, 9 ; Luc, $4,26$.

154. Achille Tatius, II, 17.

155. Xénophon, Anabase I, 4, 5, comme Skylax, 102, indique par exemple la présence de colonies phéniciennes dans la partie est de la côte cilicienne. Ils présentent également Myriandros, en face d'Aigeai sur le golfe d'Issos, comme une cité phénicienne. L'emploi, ensuite, de l'écriture et de la langue phénicienne en Cilicie fait débat dans cette région essentiellement louvite. Pour LEBRUN (1987) et W INTER (1979), par exemple, l'inscription phénicienne de Karatepe de la deuxième moitié du VIII ${ }^{\mathrm{e}}$ siècle (les inscriptions de Cineköy et de Hassan-Beyli également) comme la forte influence phénicienne d'un point de vue stylistique des sculptures de la forteresse attesteraient de l'existence de «colonies » commerciales phéniciennes établies en Cilicie. Contra CASABONnE (2004), p. 69 et LEMAIRE (2001), qui pensent que le phénicien est avant tout une langue écrite, une langue «culturelle », et qu'elle n'est probablement pas la langue parlée localement. On rappellera également les liens d'Ura avec la syrienne Ougarit et les échanges culturels intenses avec Chypre qui accueille de nombreuses colonies phéniciennes.

156. Miracles de sainte Thècle, $11 ; 18 ; 40$. Cf. NISSEN (2001), p. 118-121.

157. Miracles de sainte Thècle, 11.

158. Cf. NISSEN (2001), p. 130.

159. MASSON (1982).

160. LIPINSKI (1995), p. 194-195, avec réf.

161. Le nom de la cité phénicienne est le plus souvent transcrit en «Sarepta», parfois « Sarapta ".

162. LIPINSKI, ibid.

163. LIPINSKI (1995), p. 162.

164. Damascius, Vie d'Isidore, 302.

165. LIPINSKI, ibid. p. 195 avec réf.

166. LIPINSKI, ibid. Voir aussi PUECH (1986), p. 33. Il est par ailleurs intéressant de noter que plusieurs toponymes "Sarpédon » sont des caps et l'on pourrait faire le rapprochement avec le «Cap d'Eshmun » (R'ššsmn), le « Cap d'Apollon » des Romains et des Grecs, l'actuel cap Sidi Ali elMekki dans le golfe de Tunis, qui annonçait l'importance du culte d'Eshmun à quiconque s'approchait des côtes puniques : cf. LIPINSKI (1995), p. 162.

167. PUECH, ibid., p. 342. 
168. Voir supra.

169. Voir supra, note 155.

170. Pour expliquer le rapprochement entre Resheph et Shadrapha, E. Puech souligne notamment que l'on connaît à Pyla à Chypre une dédicace du viI ${ }^{\mathrm{e}}$ siècle av. J.-C. au dieu ReshephShed (KT 1143). Resheph est ici associé au dieu Shed qui est lié à la racine rp' "guérir » dans le théonyme šdrp' (Shadrapha) en Phénicie et qui, en Égypte, a les fonctions d'un dieu protecteur et guérisseur. Cf. PUECH, ibid., p. 337.

171. PUECH, ibid., p. 338-339.

172. Strabon, XVI, 2, 13. Nous remarquons ici que nous restons toujours dans la sphère culturelle sidonienne.

173. Puech, ibid. p. 338. À propos des divinités guérisseuses qu'il étudie, E. Puech « se demanderait même si Amrit-Marathos n'a pas joué un rôle dans la diffusion de ce culte à Chypre (Kition et environs) puisque le site d'Amrit par ses témoignages archéologiques pourrait avoir servi de relai, géographiquement et chronologiquement ». Avec Chypre, le cap Sarpédon ou la cité du même nom auraient-ils pu constituer des étapes ultérieures dans la diffusion de ce culte?

\section{RÉSUMÉS}

Apollon Sarpédonios, le grand dieu de Séleucie-du-Kalykadnos en Cilicie, fait l'objet d'un culte oraculaire renommé dans le monde antique aux époques hellénistique et romaine. L'analyse historique sur le temps long de cette divinité évoquant le héros Sarpédon fait apparaitre une personnalité divine complexe quelque peu éloignée des conceptions « canoniques » de l'Apollon grec. Étudié dans son contexte régional, le cas d'Apollon Sarpédonios est un exemple particulièrement révélateur des mécanismes culturels et religieux qui opèrent à Séleucie et plus généralement dans une Cilicie située au carrefour des cultures et soumises à de multiples influences culturelles tout au long de son histoire. Apparaissent alors les différentes strates culturelles qui se sont superposées en Cilicie où à l'ancien fond anatolien sont venues se mêler des influences louvite, hourrite, syro-phénicienne, perse, grecque puis romaine.

Apollo Sarpedonios, the great god of Seleukeia on the Kalykadnos in Cilicia, is the subject of a famous oracular cult in the ancient world in the Hellenistic and Roman periods. The historical analysis on the long time of this divinity evoking the hero Sarpedon reveals a complex divine personality somewhat distant from the "canonical" conceptions of the Greek Apollo. The case of Apollo Sarpedonios, studied in its regional context, is a particularly revealing example of the cultural and religious mechanisms that operate in Seleucia and more generally in a Cilicia situated at the crossroads of cultures and subjected to multiple cultural influences throughout its history. It highlights the different cultural strata that mixed in Cilicia, where Luwian, Hurrian, Syro-Phoenician, Persian, Greek and then Roman cultural influences enriched the ancient Anatolian background. 


\section{AUTEUR}

\section{ADRIEN BERTHOU}

Université Bordeaux Montaigne-Ausonius (UMR 5607)

adrien.berthou1@etu.u-bordeaux-montaigne.fr 